\title{
La historia que nos cuenta la cerámica de la ciudad de Machaquila, Petén, Guatemala
}

\author{
Ma Josefa Iglesias Ponce DE LEÓN \\ Dep. de Historia de América II (Antropología de América) \\ Universidad Complutense de Madrid \\ pepaipdl@ghis.ucm.es
}

Recibido: 15 de octubre de 2010

Aceptado: 19 de octubre de 2010

\begin{abstract}
RESUMEN
El estudio de los materiales cerámicos forma parte importante tanto de las tareas de prospección como de excavación arqueológica, y su posterior tratamiento y clasificación incide de forma esencial en los trabajos de interpretación de los yacimientos con ellos relacionados. En esta aportación se realiza una aproximación a la cerámica del sitio maya clásico de Machaquila, en el Petén guatemalteco, tanto a nivel particular como, fundamentalmente, en relación con la secuencia realizada con los más de 300 sitios investigados por el Atlas Arqueológico de Guatemala en los -por ahora- casi 25 años de historia (1987-2011), entre los que se encuentra Machaquila.
\end{abstract}

Palabras claves: Cultura maya, cerámica, secuencia del Sureste de Petén, Machaquila

\section{The Story That Pottery Tells From the City of Machaquila, Petén, Guatemala} \begin{abstract}
The study of ceramic materials is an important part of archaeological survey and excavation, in that their treatment and classification have a significant impact on the interpretation of sites associated with them. This paper presents a study of the pottery of the Classic Maya site of Machaquila (Petén, Guatemala) as a set of evidence in its own right but, above all, in relation to the overall ceramic sequence for the Southeast Petén. This region consists of more than 300 sites, among them Machaquila, that have been investigated systematically by the Atlas Arqueológico de Guatemala during its first 25 years of existence (1987-2011).
\end{abstract}

Key words: Maya culture, pottery, ceramic sequence from the Southeast Petén, Machaquila

Sumario: 1. La secuencia cerámica del Sureste de Petén. 2. La cerámica de Machaquila. 3. La cerámica de Machaquila y su relación con la secuencia cerámica del Sureste de Petén. 4. La historia que nos cuenta la cerámica: reflexiones finales. 5. Referencias bibliográficas.

\section{La secuencia cerámica del Sureste de Petén}

En el año 2007, y después de 20 años de trabajo de campo arqueológico en un amplio espacio del Sureste de Petén cercano a los $9.000 \mathrm{~km}^{2}$, Juan Pedro Laporte concluyó una de las tareas en las que más empeño y constancia había puesto en los últimos años de su vida: la publicación en formato digital, y su inmediata presencia en la página web del Atlas Arqueológico de Guatemala (www.atlasarqueologico.com), de la secuencia cerámica del Sureste de Petén (Laporte 2007).

Esta investigación se ha realizado en el marco del Proyecto «La entidad política de Machaquilá (Guatemala) durante el Clásico Tardío y Terminal», financiado sucesivamente por el Ministerio de Cultura (años 2001 y 2002) y por el Ministerio de Ciencia y Tecnología y Ministerio de Educación ( $\mathrm{N}^{\circ}$ de Referencia: BHA 200203729) entre 2003 y 2005.

N. del E.: Por deseo expreso de la autora, en este artículo se sigue la convención vigente en Guatemala (Acuerdos Gubernativos 1046-87 y 129-88) de no usar tilde en los nombres procedentes de lenguas indígenas. En su pronunciación, las palabras mayas o derivadas de ellas -incluyendo «Machaquila»-son agudas. 
Este magno compendio había estado precedido de, al menos, dos publicaciones previas. La primera de ellas, en 1993 (Laporte et al. 1993), se basaba en los materiales recolectados en el sitio principal de Ixtonton, que proporcionó una amplia -aunque irregular- secuencia temporal desde el Preclásico Tardío al Postclásico ${ }^{1}$. Pero la continuidad de los trabajos de exploración y excavación del Atlas Arqueológico de Guatemala (véase el registro de sitios más actualizado en Atlas Arqueológico de Guatemala 2008), hizo plantear una actualización de la secuencia (Laporte 1995), incluyendo nuevas muestras, mayoritariamente procedentes de yacimientos del noroeste de la meseta de Dolores, como Ixkun, Curucuitz, Sacul o Yaltutu. La presencia de nuevos materiales, además de significar un enriquecimiento de la secuencia, supuso la aparición de aspectos específicos para el área, tales como la constatación de una esfera cerámica adicional entre el Preclásico Tardío y el Clásico Temprano, nominada Chicanel Periférico (siglos V y VI d.C.).

Un punto de inflexión fundamental para el Atlas está en el hecho de haber transcendido sus primeros límites, coincidentes con los del municipio de Dolores, abarcando nuevas áreas de características ecológicas diferentes, con lo que la secuencia cerámica se fue enriqueciendo, y por ello transformando, con nuevas muestras procedentes tanto de sitios centrales como habitacionales, e incluso de contextos específicos como las cuevas. Poco a poco fue evidente -como no podía ser de otra manera- la existencia de una diversidad cerámica mucho mayor que la esbozada en los primeros trabajos, retrotrayendo el poblamiento al Preclásico Medio, y consolidando el resto de los complejos cerámicos preclásicos y especialmente clásicos. Asimismo dejó en evidencia una problemática de gran interés: la necesidad de trabajar de forma específica el periodo Postclásico, que presentaba unas carencias que lo situaban en un plano poco comparable con otras zonas de las Tierras Bajas Centrales (Laporte 2007: 3).

Si bien es cierto que en cada Reporte anual del Atlas Arqueológico de Guatemala se incluía un estudio de los materiales correspondientes a las nuevas exploraciones, realizado por sus propios responsables, fue Juan Pedro Laporte quien, dentro del Atlas Arqueológico, asumió la tarea de ir elaborando y refinando una clasificación esencial, que cada año iba aumentando sus bases y, con ello, proporcionando a los proyectos arqueológicos peteneros y beliceños un instrumento comparativo impagable con el que establecer nuevos puntos de referencia en sus propias colecciones. A lo largo de los años de existencia del Atlas no hubo proyecto arqueológico que dejara de enviar al laboratorio de Dolores arqueólogos y ceramólogos para recibir información de primera mano sobre los nuevos avances de la secuencia, intercambiar opiniones de cuestiones formales o metodológicas y, en suma, contar con información rigurosa, inmediata, abierta y directa, aspectos estos que estuvieron en la filosofía de trabajo de Juan Pedro Laporte desde los inicios de su carrera científica, y a quien las nuevas tecnologías informáticas ayudaron a ver hecho realidad su sueño de que la accesibilidad a la información debía ser una constante en la actividad arqueológica, una forma de actuación incuestionable en el presente y el futuro de la arqueología guatemalteca. De ahí su empeño en la realización de los ya indispensables Simposios de Investiga-

\footnotetext{
1 En la muestra, las etapas de mayor debilidad presencial eran el Clásico Temprano y el Postclásico. La secuencia se reforzó, poco después, con la muestra procedente de la cueva Aktun Ak'Ab (Rodas y Laporte 1995), cercana a Ixtonton.
} 
ciones Arqueológicas en Guatemala, la inmediatez de su publicación y el impagable paso final de su acceso abierto en la web.

Introduciéndonos ya en aspectos más técnicos, se remite al lector a la introducción que Laporte (2007: 3-10) realiza en su aportación, ya que sistematiza de una forma clara y precisa el porqué de la aplicación del Sistema Tipo-Variedad en el área Maya, y tanto su validez como sus limitaciones, aportando una historia de la aplicación del sistema desde sus inicios, a partir de materiales cerámicos procedentes fundamentalmente de sitios únicos y sobre elementos completos, y cómo ha ido evolucionando ajustándose a otro tipo de estudios como los realizados por el Atlas Arqueológico de Guatemala.

La experiencia de visionar muchos miles de fragmentos cerámicos durante tantos años, le proporcionó una clara perspectiva de los pros y los contras de una clasificación que presenta un grado de complejidad elevado, plenamente acorde con una sociedad como la maya para cuyo estudio nació y evolucionó. Aboga, asimismo, por tratar de transcender los niveles puramente cronológicos y espaciales - esenciales por otra parte en los estudios arqueológicos- para extraerle un tipo de información más relacionada con otros aspectos culturales donde la cerámica estuvo presente.

Del mismo modo es muy clarificadora la parte introductoria procedente de la tesis doctoral de nuestra colega Mélanie Forné (2005), donde aborda de una forma exhaustiva -tal y como corresponde a un serio trabajo de recopilación como el suyo-todos aquellos aspectos que pueden ayudar en una mayor comprensión de los materiales cerámicos, dando una importancia considerable, tal y como también lo hace Laporte (2007: 9-20), al concepto de modo cerámico². Este concepto viene sin duda a complementar sobremanera el análisis Tipo-Variedad, corrigiendo algunos de los fallos que pueda tener la tipología, refinando en ocasiones la cronología de un sitio específico y ayudando, lo cual es de gran importancia, a clasificar ese gran porcentaje de fragmentos cerámicos sumamente erosionados presentes en todas las excavaciones.

Dado que, especialmente si nos encontramos con unos volúmenes grandes de material, la aparición de atributos dentro de los diferentes modos puede multiplicarse hasta hacerse inmanejable ${ }^{3}$, es el ceramólogo quien decide el número de modos. En la secuencia cerámica del Sureste de Petén, dentro del análisis, se dio una mayor importancia al modo morfológico, es decir a las formas genéricas (aunque, con posterioridad se pasó a las formas específicas definidas a partir de atributos particulares), que como bien apunta Laporte (2007: 11) «proporcionan una idea general de las funciones inherentes del material cerámico en una sociedad y, dada la condición general del análisis, permite observar colecciones numerosas de tiestos».

\footnotetext{
2 «El concepto de modo cerámico corresponde a Irving Rouse, al considerarle como un atributo que tiene alguna importancia de tipo histórico, es decir, que es significativo y que posee una importancia y significado particular mayor que un rasgo puramente descriptivo» (Laporte 2007: 9). Forné (2005: 100-109, Fig. 3.2) los jerarquiza en cuatro: morfológicos, decorativos, técnicos y compuestos. A su vez se subdividen en 12 subcategorías, que se dividen nuevamente en función de sus necesidades.

3 Por ejemplo, en el caso de las excavaciones de La Joyanca la clasificación se realizó sobre un total de 64.460 tiestos y 44 piezas completas o semicompletas, y a partir de ello se seleccionaron 150 modos correspondientes a 19.686 apariciones diferenciables (Forné 2005: 106-109), los cuales se consideraron como diagnósticos y relevantes para establecer la secuencia.
} 
Por último, recordemos que al estar tratando con una amplia zona geográfica de características relativamente variadas, como es el sureste y centro-oeste de Petén, el estudio arqueológico en general -y el cerámico en particular- se realizó a partir de la presencia de diferentes cuencas fluviales, que se subdividen según su altitud en el paisaje que recorren ${ }^{4}$. Específicamente, el sitio de Machaquila se inscribe en la Vertiente Usumacinta u Occidental, en la Cuenca Baja del río Machaquila.

\section{La cerámica de Machaquila}

En el artículo general de este dossier se han avanzado las características de las excavaciones arqueológicas realizadas en Machaquila y a dichas características está evidentemente atado el material recuperado en el trascurso de ellas. Con todo, y a pesar de las limitaciones con las que se trabajó, pensamos que se cuenta con una muestra suficiente para dar idea del universo en que se movió la corta y efímera, aunque apasionante, historia de Machaquila, a nivel interno y a nivel regional. Conocemos la cerámica del día a día de la ciudad, tanto la usada por sus élites como por su gentes del común; también aquellos materiales especiales presentes en determinados rituales realizados en torno a sus plazas centrales, si bien somos conscientes de que quedaría un importante aspecto sin tratar, pero que puede ser solventado en años venideros: la vertiente funeraria, aunque cabe pensar que no sería muy diferente de la que se encuentra presente en ciudades de su época y mismo nivel de complejidad.

Asimismo, por lo adelantado en el apartado introductorio de esta aportación, el lector puede deducir que nuestro estudio sigue plenamente las líneas maestras presentes en el Atlas Arqueológico de Guatemala, pero dado el peculiar desarrollo cultural de nuestra ciudad, y por ello la desigualdad en la presencia de materiales de los distintos periodos, en unos casos -aquellos minoritarios como los de Preclásico Tardío, Clásico Temprano y Postclásico- los materiales se presentan en cuadros que indican su contexto específico, además de los correspondientes cuadros generales de relación con la secuencia general del Atlas. No se presenta en esta ocasión este mismo trabajo para los periodos mayoritarios (Clásico Tardío y Terminal) por lo excesivamente prolijo de los datos que haría sus cuadros poco operativos.

Existen ciertos contextos que en ocasiones pueden diluir su importancia dentro de la clasificación, como el denominado Cuadrilobulado o algunas concentraciones de material y escondites, por lo que se hará referencia breve, pero específica, a ellos.

\section{La cerámica de Machaquila y su relación con la secuencia cerámica del Su- reste de Petén}

Aunque sea pecar de redundante, es necesario recordar el hecho de que el trabajo del Atlas Arqueológico se fundamenta en un reconocimiento extensivo más que en

\footnotetext{
${ }^{4}$ En esta división se define a las cuencas altas como aquellas que corresponden al área montañosa y se nomina cuencas bajas cuando recorren las sabanas. Para una información más amplia ver Laporte 2007: 22-27. 
excavaciones en profundidad; es por ello que determinado tipo de afirmaciones pueden variar en un futuro, porque se trabaje de forma más intensa en localizaciones precisas que puedan aportar materiales tempranos. Lo cierto, en la actualidad, es que apenas se puede hacer una somera referencia a los materiales de periodos tempranos, PreMamom, ya que a pesar de estar presentes en al menos cinco complejos en una buena parte de las Tierras Bajas Mayas, no ha sido posible establecer una tipología firme para el Sureste de Petén (Laporte y Alvarado 1999).

\subsection{Periodos Preclásico Medio y Tardio}

Para la esfera Mamom (Preclásico Medio, Complejo Resumidero-Carrizal-Nances), sí se cuenta ya con una serie de materiales cerámicos que, si bien son escasos $(\mathrm{n}=2.910)$, tienen ya una amplia variedad y nos informan de la presencia efectiva (detectados en 21 sitios) de comunidades agrícolas asentadas en las fértiles vegas, las cuales cuentan asimismo con arquitectura y artefactos líticos especializados (Laporte 2007: 30). El Preclásico Tardío (Esfera Chicanel, Complejos Atzante-Las Lajas-Sijón, $\mathrm{n}=20.003$; detectados en 105 sitios) muestra una fuerte ocupación de diversos sectores del Sureste de Petén y se observa una clara integración cultural con el resto de las Tierras Bajas a todos los niveles, donde la uniformidad cerámica es un simple reflejo de la uniformidad a nivel de sistema cultural.

Con respecto a Machaquila, a partir de las excavaciones realizadas y los trabajos de limpieza y reconocimiento de saqueos intrusivos, se hace evidente -por el momento- la nula presencia de poblamiento en el periodo Preclásico Medio (Complejos Resumidero-Carrizal-Nance), aunque sí se ha detectado una pequeña muestra (Cuadro 1) de 27 fragmentos cerámicos del Preclásico Tardío (Complejos Atzante-Las LajasSijón, $n=12.571$ ), en ningún caso relacionados con arquitectura propia u otro tipo de rasgo cultural.

En todos los casos los fragmentos pertenecen a la Clase Paso Caballos Ceroso, que en este sentido se ajusta a la aparición general en la Secuencia del Atlas de este complejo, en el que es claramente mayoritario: $62,8 \%$ de Clase Paso Caballos Ceroso frente a 35,6\% de Clase Uaxactun Sin Engobe. De los 11 grupos presentes en la secuencia, sólo contamos con una muestra de cuatro, que son los mayoritarios: Flor, Sierra, Polvero y Con Color Diferenciado (Cuadro 2).

Aunque puede no ser significativo, al tratarse de una muestra menor, es interesante apuntar que en ella el Grupo Flor es claramente mayoritario $(n=16)$, con dos tipos representados: Flor Crema: Flor ( $\mathrm{n}=14)$ y Flor Crema: Luciano $(\mathrm{n}=2)$, que aglutinan más de la mitad de la muestra de Machaquila (59,25\%), mientras que en la secuencia general estos dos tipos representaban sólo el 12,8 \%. En cambio, el grupo más abundante de la secuencia general es el Grupo Sierra (un $48 \%$ de la Clase, en este caso con sólo dos tipos el 44,5\%), que en Machaquila se sitúa en segundo lugar ( $n=7$; $25,9 \%$ ); también varía considerablemente el porcentaje del tipo Velorio BícromoCrema Exterior $\mathrm{n} / \mathrm{d}$ / Negro Interior $(\mathrm{n}=3)$, dentro del Grupo con Color Diferenciado, que es el tercero en aparición de Machaquila pero que destaca sobremanera al suponer un $11,1 \%$ frente al $0,47 \%$ que supone en la secuencia general. Por último, la menor 
Cuadro 1: Localización de cerámica del Preclásico Tardío en Machaquila

\begin{tabular}{|c|c|c|c|c|}
\hline Localización & Clase & Grupo & Tipo & n \\
\hline Estructura 20 & $\begin{array}{l}\text { Paso Caballos } \\
\text { Ceroso }\end{array}$ & $\begin{array}{l}\text { Con Color } \\
\text { Diferenciado }\end{array}$ & $\begin{array}{l}\text { Velorio Bícromo (Crema Exte- } \\
\text { rior } \mathrm{n} / \mathrm{d} / \text { Negro Interior) }\end{array}$ & 1 \\
\hline \multirow[t]{4}{*}{ Cuadrilobulado } & $\begin{array}{l}\text { Paso Caballos } \\
\text { Cerosos }\end{array}$ & Flor & Flor Crema Flor & 8 \\
\hline & $\begin{array}{l}\text { Paso Caballos } \\
\text { Ceroso }\end{array}$ & Flor & Flor Crema: Luciano & 2 \\
\hline & $\begin{array}{l}\text { Paso Caballos } \\
\text { Ceroso }\end{array}$ & Sierra & Sierra Rojo: Sierra & 1 \\
\hline & $\begin{array}{l}\text { Paso Caballos } \\
\text { Ceroso }\end{array}$ & Sierra & Laguna Verde Inciso: Sereque & 1 \\
\hline \multirow[t]{2}{*}{ Estructura 26} & $\begin{array}{l}\text { Paso Caballos } \\
\text { Ceroso }\end{array}$ & Flor & Flor Crema & 2 \\
\hline & $\begin{array}{l}\text { Paso Caballos } \\
\text { Ceroso }\end{array}$ & $\begin{array}{l}\text { Con Color } \\
\text { Diferenciado }\end{array}$ & $\begin{array}{l}\text { Velorio Bícromo (Crema Exte- } \\
\text { rior n/d/ Negro Interior) }\end{array}$ & 2 \\
\hline \multirow[t]{2}{*}{ Estructura 31} & $\begin{array}{l}\text { Paso Caballos } \\
\text { Ceroso }\end{array}$ & Flor & Flor Crema & 1 \\
\hline & $\begin{array}{l}\text { Paso Caballos } \\
\text { Ceroso }\end{array}$ & Sierra & $\begin{array}{l}\text { Laguna Verde Inciso Sereque } \\
\text { (acanalado-inciso) }\end{array}$ & 1 \\
\hline $\begin{array}{l}\text { Cuadrángulo } \\
\text { (Estructuras } 38 \text { a 41) }\end{array}$ & $\begin{array}{l}\text { Paso Caballos } \\
\text { Ceroso }\end{array}$ & Sierra & $\begin{array}{l}\text { Laguna Verde Inciso Sereque } \\
\text { (acanalado-inciso) }\end{array}$ & 1 \\
\hline Estructura 4 & $\begin{array}{l}\text { Paso Caballos } \\
\text { Ceroso }\end{array}$ & Flor & Flor Crema & 1 \\
\hline $\begin{array}{l}\text { Estructura 10: Basurero } \\
\text { PSP-41 }\end{array}$ & $\begin{array}{l}\text { Paso Caballos } \\
\text { Ceroso }\end{array}$ & Flor & Flor Crema & 1 \\
\hline \multirow[t]{2}{*}{ Estructura 10} & $\begin{array}{l}\text { Paso Caballos } \\
\text { Ceroso }\end{array}$ & Flor & Flor Crema & 1 \\
\hline & $\begin{array}{l}\text { Paso Caballos } \\
\text { Ceroso }\end{array}$ & Polvero & Polvero Negro & 1 \\
\hline $\begin{array}{l}\text { Pozo entre basamento de } \\
\text { E-10 y Plaza F }\end{array}$ & $\begin{array}{l}\text { Paso Caballos } \\
\text { Ceroso }\end{array}$ & Sierra & Sierra Rojo: Sierra & 1 \\
\hline $\begin{array}{l}\text { Escalinata de acceso a la } \\
\text { plaza E }\end{array}$ & $\begin{array}{l}\text { Paso Caballos } \\
\text { Ceroso }\end{array}$ & Sierra & $\begin{array}{l}\text { Laguna Verde Inciso Sereque } \\
\text { (acanalado-inciso) }\end{array}$ & 1 \\
\hline $\begin{array}{l}\text { Estructura } 7 / 8 \text { (sector norte, } \\
\text { bajo el piso de la Plaza F) }\end{array}$ & $\begin{array}{l}\text { Paso Caballos } \\
\text { Ceroso }\end{array}$ & Sierra & Sierra Rojo: Sierra & 1 \\
\hline TOTAL & & & & 27 \\
\hline
\end{tabular}

Cuadro 2: Comparación en número y porcentajes de las clases y grupos cerámicos del Preclásico Tardío entre Machaquila y la secuencia general del Sureste

\begin{tabular}{llrrrr}
\hline \multicolumn{1}{c}{ Clase } & \multicolumn{1}{c}{ Grupo / Tipo } & \multicolumn{2}{c}{ Machaquila } & \multicolumn{2}{c}{ Secuencia general } \\
& & n & \multicolumn{1}{c}{$\%$} & \multicolumn{1}{c}{$\mathbf{n}$} & \multicolumn{1}{c}{$\%$} \\
\hline Paso Caballos & Con Color Diferenciado / Velorio Bícromo & 3 & 11,11 & 60 & 0,47 \\
Ceroso (62,8\% de la & Flor / Flor Crema Flor & 14 & 51,85 & 1.462 & 11,60 \\
Secuencia General) & Flor / Flor Crema: Luciano & 2 & 7,41 & 146 & 1,16 \\
& Sierra / Sierra Rojo: Sierra & 3 & 11,11 & 5.006 & 39,80 \\
& Sierra / Laguna Verde Inciso: Sereque & 4 & 14,81 & 564 & 4,48 \\
& (acanalado-inciso) & & & & \\
(Otras) & Polvero / Polvero Negro & 1 & 3,70 & 1.165 & 9,30 \\
TOTAL & & - & & 4.168 & 33,15 \\
\hline
\end{tabular}


representación está en el tipo Polvero Negro ( $\mathrm{n}=1 ; 3,7 \%)$, mientras que su importancia en la secuencia general alcanza el 9,3\%.

En resumen, la diversidad de contextos (estructuras de diferente rango, basureros, plazas o recinto ceremonial -el cuadrilobulado de la Plaza A-) en que aparecen los 27 fragmentos clasificados no dan muchas opciones interpretativas, ya que sólo algunos de ellos hacen su aparición bajo pisos sellados, pero en ningún caso guardan relación con arquitectura propia que pueda apoyar un poblamiento temprano. El hecho de que, aunque pequeño, el material cerámico presente corresponda sola y exclusivamente a piezas engobadas, y no a cerámica utilitaria, también incidiría en que no estamos, por lo que sabemos hasta el momento, ante un asentamiento formalizado.

\subsection{Periodo Clásico Temprano}

Para el siguiente periodo, el Clásico Temprano (Complejo Concoma, para las cuencas fluviales occidentales) contamos con una representación aún menor, no sólo en la ciudad, sino en general en la calificada como Cuenca Baja del río Machaquila, estando además sólo presente, casi testimonialmente, en la cueva de San Miguel (Poptun) (Laporte 2007: 528).

Aunque no es este el espacio adecuado para abordar la problemática del Clásico Temprano en la Tierras Bajas (ver Laporte 2007: 507-510), sí es necesario apuntarlo brevemente ya que Machaquila participa, aunque sin duda muy someramente, de él.

$\mathrm{Al}$ igual que sucedía en periodos anteriores, hay que partir de la base de una clasificación aportada desde ciertas grandes ciudades de la Tierras Bajas Centrales; específicamente como entidad cerámica, el Clásico Temprano tiene ya una vigencia de más de 80 años (Merwin y Vaillant 1932: 65-71; Vaillant 1927: 303-306), desde que fue enunciada para Holmul, y no ha sido prácticamente discutida por ninguno de los trabajos posteriores en dichas grandes urbes. Apenas hay unos tímidos cuestionamientos en los años 70 y 80, abogando por unas maneras más flexibles en relación con el estudio de los materiales cerámicos (Lincoln 1985), pero lo cierto es que será en las investigaciones realizadas fuera de las poblaciones centrales -Belice y sureste y centro-oeste de Petén- donde se ha impulsado una propuesta alternativa (Laporte 2007: 508-510).

El hecho fundamental estriba, entre otros aspectos, en la coexistencia de materiales pertenecientes a las esferas cerámicas Chicanel y Tzakol en contextos arqueológicos primarios, al tiempo que en grandes áreas -especialmente habitacionales- la ausencia de materiales del Clásico Temprano llevarían a formular un abandono hasta el Clásico Tardío, aunque arqueológicamente no se constate ningún estrato especifico de abandono de los sitios.

En ciertos casos se han ido aportando soluciones «particulares», llegando incluso a formularse una etapa de transición denominada Preclásico Terminal (Belice y Cuenca de Mirador, por ejemplo). En el sureste de Petén, Laporte (2007: 539-543) aboga por un modelo de regionalización cerámica que implica unos cambios claros y efectivos en los grandes contextos elitistas del noreste de Petén, como Tikal, Uaxactun y Yaxha, que conviven y comparten dichos cambios -en menor medida- con otros centros menores como Ceibal, Cerros, Río Azul o Piedras Negras; pero en localizaciones aún 
Cuadro 3: Localización de cerámica del Clásico Temprano en Machaquila

\begin{tabular}{llllr}
\hline \multicolumn{1}{c}{ Localización } & \multicolumn{1}{c}{ Clase } & \multicolumn{1}{c}{ Grupo } & \multicolumn{1}{c}{ Tipo } & n \\
\hline Grupo Habitacional 7, Estruct. 4 & Petén Lustroso & Águila & Águila Rojo/Naranja & 1 \\
Cuadrángulo (Estructs. 38 a 41) & Petén Lustroso & Águila & Águila Rojo/Naranja & 7 \\
& Petén Lustroso & Pucté & Pucté Café & 4 \\
Estructura 10 & Uaxactun sin Engobe & Triunfo & Triunfo Estriado & 1 \\
& Petén Lustroso & Águila & Águila Rojo/Naranja & 1 \\
Estructura 3 & Petén Lustroso & Águila & Águila Rojo/Naranja & 1 \\
& Petén Lustroso & Dos Arroyos & Dos Arroyos Naranja & 1 \\
TOTAL & & & Policromo & 16 \\
\hline
\end{tabular}

más rurales y alejadas, como el caso del sureste de Petén, donde la organización sociopolítica es mucho más endeble, habrá una mayor persistencia de la gran esfera Chicanel a todos los niveles, aunque obviamente en el transcurso del periodo las elites fueron teniendo una mayor participación en las modas de los grandes centros, y es por ello que -aunque de forma minoritaria- afloran las cerámicas puramente Tzakol.

¿Cómo influye esto en nuestro yacimiento? Como se puede apreciar en el Cuadro 3, las cantidades presentes son mínimas: un fragmento para cerámica utilitaria y 15 para la cerámica engobada. A pesar de ser una muestra reducida, tiene un grado de dispersión mucho menor que los materiales del Preclásico Tardío: un grupo pequeño habitacional del extrarradio (GH 7), El Cuadrángulo y las Estructuras 3 y 10 (plataformas bajas pero en el entorno de la Plaza F que será de importancia residencial con posterioridad), localizadas en la zona norte de la ciudad.

Las comparaciones con la secuencia general (Cuadro 4) no son relevantes, ya que, aunque está presente un tipo utilitario (Triunfo Estriado), el resto de los fragmentos engobados suponen el 93,75\%, un enorme desequilibrio con respecto al 55,8\% que alcanzan los mismos tipos cerámicos engobados en la secuencia general. Laporte (2007: 531) piensa que estos ejemplares pudieron llegar a través de los centros situados en la parte más septentrional del Medio Mopán.

Las coincidencias de contextos de Chicanel y Tzakol se limitan a la Estructura 10 de la Plaza F y al llamado Cuadrángulo (Estructuras 38 a 41), pero en la primera lo-

Cuadro 4: Comparación en número y porcentajes de las clases y grupos cerámicos del Clásico Temprano presentes en Machaquila y los de la secuencia general del Sureste

\begin{tabular}{|c|c|c|c|c|c|c|}
\hline \multirow[t]{2}{*}{ Clase } & \multirow[t]{2}{*}{ Grupo } & \multirow[t]{2}{*}{ Tipo } & \multicolumn{2}{|c|}{ Machaquila } & \multicolumn{2}{|c|}{ Secuencia general } \\
\hline & & & $\mathbf{n}$ & $\%$ & n & $\%$ \\
\hline \multicolumn{7}{|c|}{ CLASE SIN ENGOBE } \\
\hline Uaxactun sin Engobe & Triunfo & Triunfo Estriado & 1 & 6,25 & 585 & 4,82 \\
\hline \multicolumn{7}{|c|}{ CLASE CON ENGOBE } \\
\hline \multirow[t]{3}{*}{ Petén Lustroso } & Águila & Águila Rojo/Naranja & 10 & 62,50 & 637 & 5,25 \\
\hline & Pucté & Pucté Café & 4 & 25,00 & 173 & 1,42 \\
\hline & Dos Arroyos & $\begin{array}{l}\text { Dos Arroyos Naranja } \\
\text { Policromo }\end{array}$ & 1 & 6,25 & 100 & 0,82 \\
\hline (Otras) & & & - & & 10.648 & 87,69 \\
\hline TOTAL & & & 16 & & 12.143 & \\
\hline
\end{tabular}


calización es interesante que, en dos ocasiones, compartan niveles estratigráficos bajo piso, si bien en uno de ellos aparece asimismo Clásico Tardío. Sin duda y, aunque cabe la posibilidad de plantear la realidad de un pequeño poblamiento con las características apuntadas, es evidente que desde Machaquila no se aporta actualmente solución alguna al problema de la presumible coexistencia de las esferas cerámicas Chicanel y Tzakol, en un modelo puramente regional donde las élites fueron asumiendo patrones del Clásico Temprano, mientras la población en general perpetuaba durante un tiempo las modas del Preclásico (Laporte 2007: 539-543).

\subsection{Periodo Clásico Tardio}

En el Clásico Tardío (550-800 d.C.) la presencia de material cerámico aumenta de forma general en todas las vertientes trabajadas para la secuencia general del Atlas Arqueológico (18 unidades geográficas y 131 sitios), aunque siguen siendo menos numerosos que en el del posterior periodo Clásico Terminal. Así, en la secuencia del Sureste cuenta con un total de 97.496 fragmentos de los que más del $99 \%$ pertenece a dos clases cerámicas: Uaxactun Sin Engobe (56,26\%) y Petén Lustroso (43,38\%), siendo una tercera muy reducida (Ceniza-Engobe Rojo: 0,37\%).

Al igual que sucede en el Clásico Temprano, el periodo Clásico Tardío (Complejo Río Poxte en nuestra vertiente) presenta unas ciertas peculiaridades con respecto a los fechamientos de las esferas cerámicas mayoritarias (Tepeu 1, 2 y 3), que fueron creadas a partir de unas estratigrafías arquitectónicas muy complejas, con sucesivas y constates remodelaciones, así como de la presencia de entierros de élite con ajuares cerámicos finos, como es el caso de Tikal y Uaxactun, donde pudo refinarse la presencia de Tepeu 1. Ello no es aplicable a nuestra zona ni a la mayor parte de los asentamientos conocidos del sur, el oeste y el noroeste de Petén. Sí se reconoce la posible existencia de un momento de transición entre ambos periodos Temprano y Tardío, pero no se puede realizar una aplicación sistemática fuera de las ciudades citadas. Así, los complejos cerámicos Siltok, Río Poxte y Chak'an, correspondientes a las diferentes secciones geográficas abordadas en la secuencia del Sureste de Petén, forman parte de la esfera mayor Tepeu 2 establecida para el Clásico Tardío de las Tierras Bajas (Laporte 2007: 864).

Con respecto a Machaquila, como se aprecia en el Cuadro 5, los valores en que nos movemos son relativamente reducidos $(n=679$, apenas un $0,7 \%$ de la muestra total): Clase Uaxactun Sin Engobe, n=181 (26,66\%), Clase Petén Lustroso, n=471 (69,37\%) y Clase Ceniza-Engobe Rojo, $\mathrm{n}=27$ (3,98\%).

Conociendo las características específicas de las excavaciones de Machaquila y sin ánimo de realizar una valoración estricta, es interesante apuntar el hecho de que los valores están invertidos con respecto a las medias generales de la secuencia, en la cual era mayoritaria la clase utilitaria frente a la engobada. Así, en Machaquila, la Clase Uaxactun Sin Engobe supone un 26,66\%, frente al 56,26\% de la secuencia, y dentro de la clase Petén Lustroso, Machaquila tiene por tanto unos porcentajes significativamente mayores: $69,37 \%$ frente al $43,38 \%$ de la secuencia general; destaca asimismo que la presencia en la ciudad de los grupos mayoritarios es menor (Tinaja, Máquina e Infierno, e incluso en el altamente minoritario grupo Harina), mientras que en el 
Cuadro 5: Comparación en número y porcentajes de las clases y grupos cerámicos del Clásico Tardío entre Machaquila y la secuencia general del Sureste

\begin{tabular}{|c|c|c|c|c|c|c|c|}
\hline \multirow[t]{2}{*}{ Clases } & \multirow[t]{2}{*}{ Grupos } & \multicolumn{3}{|c|}{ Machaquila } & \multicolumn{3}{|c|}{ Secuencia general } \\
\hline & & $\mathbf{n}$ & $\%$ en la clase & $\%$ & $\mathbf{n}$ & $\%$ en la clase & $\%$ \\
\hline \multicolumn{8}{|c|}{ CLASE SIN ENGOBE } \\
\hline \multirow[t]{3}{*}{ Uaxactun Sin Engobe } & Cambio & 135 & 74,58 & & 52.706 & 96,10 & \\
\hline & Encanto & 46 & 25,41 & & 2.141 & 3,90 & \\
\hline & SUBTOTAL & 181 & & 26,66 & 54.847 & & 56,26 \\
\hline \multicolumn{8}{|c|}{ CLASES CON ENGOBE } \\
\hline \multirow[t]{9}{*}{ Petén Lustroso } & Harina & 1 & 0,21 & & 498 & 1,18 & \\
\hline & Azote & 9 & 1,91 & & 579 & 1,37 & \\
\hline & Tinaja & 359 & 76,22 & & 33.569 & 79,38 & \\
\hline & Remate & 22 & 4,67 & & 605 & 1,43 & \\
\hline & Máquina & 17 & 3,60 & & 2.046 & 4,84 & \\
\hline & Infierno & 27 & 3,73 & & 2.498 & 5,91 & \\
\hline & Zacatal-Joyac & 17 & 3,60 & & 861 & 2,04 & \\
\hline & Palmar-Danta & 19 & 4,03 & & 1.633 & 3,86 & \\
\hline & SUBTOTAL & 471 & & 69,37 & 42.289 & & 43,38 \\
\hline Ceniza-Engobe Rojo & Belice Rojo & 27 & & 3,98 & 360 & & 0,37 \\
\hline TOTAL & & 679 & & & 97.496 & & \\
\hline
\end{tabular}

resto de los grupos (Azote, Zacatal-Joyac, Palmar-Danta y especialmente Remate ${ }^{5}$ con $4,67 \%$ frente a $1,43 \%$ del recuento global) están por encima de los porcentajes totales. Por último, cabe destacar el relativo alto número y porcentaje para el Grupo Belice Rojo, inscrito en la minoritaria Clase Ceniza-Engobe Rojo, que en el recuento total de la secuencia apenas suponía un $0,37 \%$, mientras que en Machaquila supone un $3,98 \%$, de su muestra, pero aún de mayor interés es el hecho de que suponga un $7,5 \%$ del total del recuento de la clase en la secuencia para este periodo.

Quizás ello guarde relación con rasgos tan diferenciados como, por una parte, el hecho de que la ciudad sea una fundación «programadamente» elitista, y por ello poseedora de un ajuar de mayor sofisticación frente a lo puramente utilitario. Por otra parte puede estar mostrando su relación con diferentes fuentes de producción cerámica: el área del Mopán cuenta con unos porcentajes significativamente mayores que el resto para la cerámica utilitaria, una mayor diversidad para la engobada (Laporte 2007: 553-557) y una relación aún más compleja con respecto a la clase Ceniza-Engobe Rojo, que podría haber entrado en el registro de Machaquila procedente de Belice a través de Calzada Mopan y Ucanal (ibid.: 858).

5 Dentro de la Clase Petén Lustroso, se introduce un nuevo grupo, Grupo Remate, que incluye tipos cerámicos que, aún con diferentes cuestionamientos, habían permanecido mayoritariamente en otros grupos, a pesar de poseer una características bien diferenciadas en cuanto a la pasta, más delgada y sonora. Así se han extraído estos fragmentos tanto del Grupo Tinaja, como sus correspondientes variaciones por color en los Grupos Máquina e Infierno (Laporte 2007: 839-840), de manera específica integran este grupo Remate los tipos de engobe rojo Aduana Rojo (v. Aduana), Pantano Impreso (vs. Pantano y Sellado) y Safir Acanalado (v. Safir); Bulbul Café (v. Bulbul) para engobe Café, y Basilio Negro (v. Basilio) y Ones Impreso (vs. Ones y Sellado) para los de engobe negro. 


\subsection{Periodo Clásico Terminal}

Tiene Juan Pedro Laporte (ibid.: 1200) buenas razones para subtitular este periodo en la secuencia cerámica como de «innovación, continuidad, alteración y conflicto», ya que, a pesar de que la variabilidad regional va a aumentar considerablemente y por ello las esferas de interacción se amplían, se hace evidente que todas ellas pertenecen a la gran esfera cerámica Tepeu 3, que emana de Tepeu 1 y 2 del Clásico Tardío. Una de las explicaciones de esta regionalización estaría en el claro detrimento socioeconómico que empiezan a sufrir los centros tradicionales más potentes, frente a áreas catalogadas hasta el momento como periféricas, que se van a ver firmemente fortalecidas. Para profundizar en diversos aspectos técnicos sobre el comportamiento de la producción y distribución cerámica que tiene lugar en las Tierras Bajas Centrales durante el Clásico Terminal, se remite al lector a la sistematización realizada por Laporte (2007: 1200-1204) a partir de los estudios de Donald Forsyth $(1998,2005)$ y su propia experiencia en las investigaciones del Atlas Arqueológico.

Este periodo es sin duda el mejor representado en la secuencia del Sureste de Petén, y no sólo a nivel numérico, ya que sus materiales aparecen en todos los sitios investigados por el Atlas Arqueológico, bien en prospección o bien en investigaciones más intensivas. Asimismo, los tres complejos que se contemplan en la actualidad para el área -Ixmabuy, Tanjoc (para la Vertiente Occidental donde se localiza Machaquila) y Tsutsuk-, son consecuencia de las diferentes versiones clasificatorias, que fueron aumentando progresivamente en categorías, tipos y variedades a medida que asimismo se fueron ampliando las zonas de prospección. En cualquier caso, y a pesar de que en unos primeros momentos la muestra se limitaba a los materiales de superficie, la posterior introducción de sondeos y excavaciones más intrusivas confirmaron la primera impresión de que dichos materiales eran plenamente representativos de la población que habitó la región a lo largo de los siglos IX y X d.C., y que existía una evidente continuidad cerámica con el periodo precedente Clásico Tardío.

Como veremos, aunque Machaquila tiene una interesante representación cerámica, coincidente con otros rasgos culturales definitorios del periodo como la arquitectura, se hace evidente que la duración en el tiempo debió ser más corta, a tenor del número de fragmentos recuperados y clasificados, que es significativamente menor (Cuadro 6), aunque -al igual que en el resto de la secuencia-con un mayor número de clases, grupos, tipos y variedades (Laporte 2007: 1206-1219).

Entrando ya en un análisis comparativo más específico, se aprecia que el recuento general de la secuencia del Atlas tiene unos porcentajes importantes de cerámica utilitaria no engobada $(46,55 \%, \mathrm{n}=58.806)$ con presencia abrumadora de la clase Uaxactun Sin Engobe (99,70\%) frente a una insignificante clase Temax Burdo $(0,30 \%)$ que adquirirá más importancia en el periodo Postclásico. Al igual que sucedía en el complejo precedente, aunque en una proporción menor, sigue existiendo una fuerte distorsión en los porcentajes de esta cerámica utilitaria entre la muestra de Machaquila $(28,85 \%)$ y la secuencia general $(46,55 \%)$.

De la misma manera, la Clase Petén Lustroso muestra asimismo una distorsión considerable (60,18\% frente al $51,43 \%$ de la secuencia), aunque también algo menor que en el Clásico Tardío. Con respecto a los grupos, el Tinaja está totalmente equilibrado 
Cuadro 6: Comparación en número y porcentajes de las clases y grupos cerámicos del Clásico Terminal entre Machaquila y la secuencia general del Sureste

\begin{tabular}{|c|c|c|c|c|c|c|c|}
\hline \multirow[t]{2}{*}{ Clases } & \multirow[t]{2}{*}{ Grupos } & \multicolumn{3}{|c|}{ Machaquila } & \multicolumn{3}{|c|}{ Secuencia general } \\
\hline & & $\mathbf{n}$ & $\%$ en la clas & $\%$ & $\mathbf{n}$ & $\%$ en la clase & $\%$ \\
\hline \multicolumn{8}{|c|}{ CLASES SIN ENGOBE } \\
\hline \multirow{3}{*}{ Uaxactun Sin Engobe } & Cambio & 103 & 79,84 & & 55.164 & 94,09 & \\
\hline & Encanto & 26 & 20,16 & & 3.465 & 5,91 & \\
\hline & SUBTOTAL & 129 & & 28,86 & 58.629 & & 46,41 \\
\hline Temax Burdo & Puluacax & - & & 0,00 & 177 & & 0,14 \\
\hline \multicolumn{8}{|c|}{ CLASES CON ENGOBE } \\
\hline \multirow[t]{10}{*}{ Petén Lustroso } & Harina & 1 & 0,37 & & 336 & 0,52 & \\
\hline & Azote & 5 & 1,86 & & 753 & 1,16 & \\
\hline & Tinaja & 221 & 82,16 & & 52.685 & 81,10 & \\
\hline & Remate & 9 & 3,35 & & 1.314 & 2,02 & \\
\hline & Máquina & 5 & 1,86 & & 1.974 & 3,04 & \\
\hline & Infierno & 5 & 1,86 & & 3.091 & 4,76 & \\
\hline & Zacatal-Joyac & 17 & 6,32 & & 2.666 & 4,10 & \\
\hline & Palmar-Danta & 6 & 2,23 & & 1.987 & 3,06 & \\
\hline & Hondo & - & & & 159 & 0,24 & \\
\hline & SUBTOTAL & 269 & & 60,18 & 64.965 & & 51,43 \\
\hline Puuc Rojo & Teabo & 2 & & 0,45 & 14 & & 0,01 \\
\hline \multirow{3}{*}{$\begin{array}{l}\text { Pine Ridge } \\
\text { Carbonatado }\end{array}$} & Mount Maloney & 1 & & 0,22 & 211 & 65,33 & \\
\hline & Dolphin Head & - & & & 112 & 34,67 & \\
\hline & SUBTOTAL & 1 & & & 323 & & 0,26 \\
\hline Ceniza-Engobe Rojo & Belice & 28 & & 6,26 & 1.523 & & 1,21 \\
\hline \multirow{4}{*}{$\begin{array}{l}\text { Naranja Fino }(2,6 \% \\
\text { sobre la muestra total) }\end{array}$} & Altar & 15 & 83,33 & & 586 & 85,80 & \\
\hline & Balancan & - & 0,00 & & 5 & 0,73 & \\
\hline & Tres Naciones & 3 & 16,67 & & 92 & 13,47 & \\
\hline & SUBTOTAL & 18 & & 4,03 & 683 & & 0,54 \\
\hline Indeterminada & Indeterminado & - & & & 1 & & 0,01 \\
\hline TOTAL & & 447 & & & 126.315 & & \\
\hline
\end{tabular}

y no existen grandes variaciones porcentuales en los grupos Harina, Azote o PalmarDanta, mientras que Infierno y Máquina se mantienen más altos en la secuencia y Remate y Zacatal-Joyac tienen una mayor presencia porcentual en Machaquila.

Con respecto a otras clases engobadas, la representación de la ya conocida clase Ceniza-Engobe Rojo, tiene fuerte aumento porcentual en la ciudad (un 6,26\% frente al 3,97\% en el Clásico Tardío) aunque apenas con respecto a su número ( 28 frente a 27 fragmentos), pero los ejemplos de la secuencia han crecido tan significativamente que apenas supone ahora un 1,83\% frente al 7,5\% del Clásico Tardío. Otras dinámicas muy diferenciadas se van a dar en la clase Puuc Rojo ( 2 fragmentos en Machaquila de los 14 de la secuencia), o de la beliceña Pine Ridge Carbonatado (1 fragmento del tipo Mount Maloney Negro en Machaquila de los 211 de la secuencia), con presencia puramente anecdótica. Estos materiales deben proceder con seguridad del intercambio con las ciudades de la cuenca del río Belice, que entran en el sureste especialmente a través de Ucanal y Calzada Mopan, expandiéndose comercialmente por otras zonas, incluyendo Machaquila. Cabe pensar, no obstante, que pudo ser manufacturada localmente en el área del medio Mopan (Laporte 2007: 1245).

Mención aparte merece la presencia de una muestra pequeña, pero suficientemente significativa (4,03\%), de la clase Naranja Fina con dos de sus grupos: Altar ( $\mathrm{n}=15$, ca- 
torce de tipo Altar Naranja y uno Trapiche Inciso) y Tres Naciones ( $\mathrm{n}=3$, tipo Tres Naciones Gris). Aunque la muestra en la secuencia general tampoco es muy abundante $(\mathrm{n}=683 ; 0,54 \%)$, como apunta Laporte (2007: 1218), la presencia de tiestos de la clase Naranja Fino es el mejor indicativo de la existencia de un Clásico Terminal en un sitio. Aún en la actualidad se encuentra cuestionado su origen y no hay datos suficientes en la secuencia general que puedan ayudar a resolver el problema, ya que, independientemente de su procedencia original, se concentran nuevamente en las ciudades del medio Mopán (más en Calzada Mopan que en Ucanal), aunque es interesante la proporción en Machaquila que puede estar mostrando asimismo una interacción diferente ${ }^{6}$.

\subsection{Periodo Posclásico Temprano}

Al igual que en periodos anteriores, la amplitud de la zona geográfica prospectada y sus especificidades planteó tres complejos cerámicos para representar el tiempo de ocupación del periodo Postclásico: Mopan para la Vertiente Oriental, Las Machacas para la Vertiente Occidental, donde se sitúa Machaquila, y Puul para el área de sabanas y lagunas del centro y centro-oeste.

La mayor parte de los autores que trabajan en las Tierras Bajas Centrales, coinciden en presentar el Postclásico como un periodo de difícil determinación e identificación en cuanto a sus materiales cerámicos, dado que una parte de las tradiciones del Postclásico Temprano poseen una fuerte continuidad con aquellas del Clásico Terminal, mientras que los momentos posteriores en que se detectan innovaciones específicas, y no sólo en aspectos cerámicos, serán los que se correspondan con el Posclásico Tardío. Al menos en lo que respecta al Sureste de Petén, es muy difícil, por no decir imposible con los datos que se tienen actualmente, realizar esta división por periodos, por lo que la referencia al Postclásico será general.

En su sistematización para este periodo, Laporte (2007: 1738-1740, 1754-1756) apunta la importancia de la cerámica para caracterizar e interpretar esta conflictiva etapa, y especialmente hace mención de los estudios realizados en Belice que, a través del material recuperado en Barton Ramie ${ }^{7}$, definieron una primera y temprana esfera para el Postclásico Temprano, detectada posteriormente en Tayasal, Macanche y Topoxte. Con posterioridad fueron las mismas investigaciones de Tayasal las que definieron la esfera cerámica para el Postclásico Tardío, manifestada asimismo en Macanche y Topoxte.

${ }^{6}$ En el punto 6 de la sistematización que Laporte (2007: 1202-1203) hace sobre la continuidad en los periodos Tardío y Terminal y de las esferas cerámicas en las Tierras Bajas, se aporta suficiente información bibliográfica sobre cómo diferentes autores apuestan por la zona Pasión-Usumacinta como lugar donde hay una mayor presencia; pero bien es cierto que con unas dinámicas bien diferenciadas según los yacimientos tratados. Así dice Laporte (ibid.: 1202): «De hecho, según esta clase de material el Clásico Terminal en esta región pareciera presentar un patrón de cambio cerámico y cultural variable. En algunos casos la cerámica de pasta fina parece representar una comunidad remanente de muy pocas personas (como en Piedras Negras); en ocasiones parece ser algo agregado al conjunto normal de la cerámica del Clásico Tardío (como en Ceibal y Petexbatun); en otras más se presenta un reemplazo total del complejo cerámico (como en Yaxchilan y Altar de Sacrificios)».

7 Con el fin de no saturar esta participación con las numerosas citas bibliográficas aportadas por Laporte (2007) en su estudio de la secuencia general del Sureste de Petén, al igual que en otras notas, se remite al lector a esta obra, por ser de fácil e inmediata consulta a través de la página web del Atlas Arqueológico de Guatemala (ver en referencias bibliográficas). 
Como salta a la vista, ello nos confirma una clara circunscripción de la ocupación a las áreas lacustres del centro de Petén, como el lago Petén Itzá y la laguna Yaxha. Fuera de esa área, si bien de una forma más o menos esporádica y siempre superficial, se ha constatado su presencia en el área de Petexbatun (Tamarindito y Punta de Chimino, Foias 1996), Ceibal (Sabloff 1975) o Altar de Sacrificios (Adams 1971). Contextos funerarios cremados se han detectado aisladamente en Dos Pilas (Escobedo et al. 1992), Piedras Negras (Houston et al. 1999), Yaxha (Hermes y Noriega 1998) y la isla de Flores (Hansen et al. 1993).

Es natural que un lugar tan emblemático como Tikal, teóricamente semiabandonado ya para ese momento, posea también algunos hallazgos en diferentes localizaciones de la ciudad, los menos de carácter funerario (Adams y Trik 1961; Culbert 1973) y otros producto de depósitos, rituales o no, esporádicos y tardíos, aunque sin datación refinada (Laporte 2003; Laporte y Herman 2003; Orrego y Larios 1983). Un interesante ejemplo nos lo muestra Forné (2005: 66, 213, 519, ilustraciones pp. 656-660) en el sitio de La Joyanca, también abandonado para esa época, de un depósito ritual -junto a un muro- compuesto por cuatro incensarios-cuenco y dos figurillas ${ }^{8}$.

Nos encontramos así con un grave problema de definición, tanto por ausencia de contextos culturales «puros» (otros que los hallazgos ocasionales ya citados), como de lo que Laporte (2007: 1755), denomina «proliferación de clases cerámicas - contra su integración en las etapas anteriores-», lo que nos da la medida de los procesos de regionalización que tienen lugar en este periodo en una gran parte de las Tierras Bajas Centrales. Un último problema, y no menor, es que, al haber permanecido durante siglos en superficie, el material suele estar en general mal preservado, sin la ventaja de haber estado «protegido» por rasgos arquitectónicos como los de periodos anteriores.

Veamos qué sucede en Machaquila durante este periodo Postclásico. El número de fragmentos rescatados $(\mathrm{n}=194)$ es significativamente menor que en los periodos Clásico Tardío y Terminal, pero con una mayor presencia y unos problemas interpretativos más complejos que en el Preclásico Tardío y Clásico Temprano. La localización de la muestra, como se aprecia en el Cuadro 7, tiene ciertas peculiaridades. Por ejemplo, dos de los grupos habitacionales del extrarradio excavados (GH 9 y GH10) poseen una pequeña muestra; en el interior de la ciudad destaca sobremanera el número de fragmentos presente en diferentes localizaciones de la Estructura $34(n=156 ; 80,4 \%)$, prácticamente todos ellos en su vertiente norte, seguida de la Estructura 4, en la Plaza F, donde se hallaron 18 fragmentos $(9,8 \%)$ y una vasija fracturada. La Estructura $7 / 8$ también tiene presencia postclásica $(n=6 ; 3,1 \%)$, así como el Basurero PSP $40(n=5$; $2,6 \%)$. En el denominado Cuadrángulo $(n=1)$ y las Estructuras $27(n=2)$ y $32(n=1)$ se cuenta con una presencia aún menor aunque, en dos casos, con características especiales como veremos en el siguiente párrafo.

La muestra de los grupos habitacionales nos remite tanto a tipos engobados (Paxcamán Rojo) como no engobados (Pozo sin Engobe); en el área central de la ciudad, la mayor diversidad se da, obviamente, en la Estructura 34 donde la cerámica no en-

${ }^{8}$ La visita de lugares abandonados, tanto de ámbito doméstico como palaciego o ritual, y la colocación de ofrendas cerámicas y líticas con actuaciones de quema de incienso, forman parte de una dinámica cultural habitual en las Tierras Bajas Mayas, incluyendo esta etapa postclásica (Chase y Chase 2004 : 21-22). 
Cuadro 7: Localización de cerámica del Postclásico en Machaquila

\begin{tabular}{|c|c|c|c|c|}
\hline Localización & Clase & Grupo & Tipo & $\mathbf{n}$ \\
\hline $\begin{array}{l}\text { Grupo Habitacional } 9 \\
\text { Estructura } 1\end{array}$ & Volador Engobe Dull & Paxcaman & Paxcaman Rojo & 2 \\
\hline $\begin{array}{l}\text { Grupo Habitacional } 9 \\
\text { Estructura } 2\end{array}$ & Uaxactun sin Engobe & Montículo (pasta gris) & Pozo sin Engobe & 1 \\
\hline $\begin{array}{l}\text { Grupo Habitacional } 10 \\
\text { Estructura } 2\end{array}$ & Uaxactun sin Engobe & Montículo (pasta gris) & Pozo sin Engobe & 1 \\
\hline $\begin{array}{l}\text { Cuadrángulo } \\
\text { (Estructuras } 38 \text { a } 41 \text { ) }\end{array}$ & Indeterminada & Indeterminado & Internacional Mixteco & 1 \\
\hline Estructura 32 & Uapake & Chilo (pasta café rojizo) & Chilo sin Engobe & 1 \\
\hline $\begin{array}{l}\text { Estructura } 34 \text { (basa- } \\
\text { mentos fachada norte) }\end{array}$ & Uapake & Chilo (pasta café rojizo) & Chilo sin Engobe & 35 \\
\hline $\begin{array}{l}\text { Estructura } 34 \\
\text { (escalinata central) }\end{array}$ & Uapake & Chilo (pasta café rojizo) & Chilo sin Engobe & 48 \\
\hline $\begin{array}{l}\text { Estructura } 34 \\
\text { (escalinata central) }\end{array}$ & Volador Engobe Dull & Paxcaman & Paxcaman Rojo & 1 \\
\hline $\begin{array}{l}\text { Estructura } 34 \\
\text { (escalinata central) }\end{array}$ & Volador Engobe Dull & $\begin{array}{l}\text { Trapiche (engobe crema } \\
\text { con pulimento) }\end{array}$ & Trapiche Rosáceo & 45 \\
\hline $\begin{array}{l}\text { Estructura } 34 \\
\text { (cuerpos superiores) }\end{array}$ & Uapake & Chilo (pasta café rojizo) & Chilo sin Engobe & 2 \\
\hline $\begin{array}{l}\text { Estructura } 34 \\
\text { (cuerpos superiores) }\end{array}$ & Volador Engobe Dull & $\begin{array}{l}\text { Trapiche (engobe crema } \\
\text { con pulimento) }\end{array}$ & Trapiche Rosáceo & 20 \\
\hline $\begin{array}{l}\text { Estructura } 34 \\
\text { (cuerpos superiores) }\end{array}$ & Volador Engobe Dull & Paxcaman & Paxcaman Rojo & 2 \\
\hline $\begin{array}{l}\text { Estructura } 34 \\
\text { (cuerpos superiores) }\end{array}$ & Volador Engobe Dull & Paxcaman & $\begin{array}{l}\text { Ixpop Policromo (sobre } \\
\text { fondo naranja) }\end{array}$ & 3 \\
\hline Estructura 4 & Uaxactun sin Engobe & Montículo ( & Pozo sin Engobe & 16 \\
\hline Estructura 4 & Uaxactun sin Engobe & Montículo (pasta gris) & La Justa Compuesto & 2 \\
\hline Estructura 4 & Uaxactun sin Engobe & Montículo (pasta gris) & Ambrosio Inciso & $1^{*}$ \\
\hline $\begin{array}{l}\text { Basurero PSP } 40 \\
\text { (Grupo G-1 escalinata } \\
\text { acceso Plaza E) }\end{array}$ & Temax Burdo & Puluacax & Puluacax Sin Engobe & 1 \\
\hline $\begin{array}{l}\text { Basurero PSP } 40 \\
\text { (Grupo G-1 escalinata } \\
\text { acceso Plaza E) }\end{array}$ & Volador Engobe Dull & Paxcaman & Paxcaman Rojo & 4 \\
\hline Estructura 27 & No Especificada & Patojo & Patojo Modelado & 2 \\
\hline Estructura $7 / 8$ & Volador Engobe Dull & Paxcaman & $\begin{array}{l}\text { Ixpop Polícromo (sobre } \\
\text { fondo naranja) }\end{array}$ & 1 \\
\hline $\begin{array}{l}\text { Estructura 7/8 } \\
\text { Basurero PSP } 49\end{array}$ & Volador Engobe Dull & Paxcaman & Paxcaman Rojo & 1 \\
\hline $\begin{array}{l}\text { Estructura } 7 / 8 \\
\text { (espacios interiores) }\end{array}$ & Volador Engobe Dull & Paxcaman & Paxcaman Rojo & 4 \\
\hline TOTAL & & & & 194 \\
\hline
\end{tabular}

${ }^{*}$ Se trata de 146 fragmentos procedentes de una misma vasija.

gobada está representada por Chilo sin Engobe $(\mathrm{n}=85)$, seguida por el tipo engobado Trapiche Rosáceo $(\mathrm{n}=65)$ y una pequeña pero interesante representación de Paxcamán Rojo (n=3) e Ixpop Polícromo ( $n=3)$. Los fragmentos hallados en la Estructura 4 pertenecen en su totalidad al grupo no engobado Montículo, pero en tres tipos diferentes: Pozo sin Engobe $(\mathrm{n}=16)$, La Justa Compuesto $(\mathrm{n}=2)$ y la vasija del tipo Ambrosio Inciso. Al contrario, la menor muestra de las Estructuras 7/8 sólo posee tipos del engobado grupo Paxcamán: Ixpop Polícromo $(n=1)$ y Paxcamán Rojo $(n=5)$. El limitado 
Cuadro 8: Comparación en número y porcentajes de las clases y grupos cerámicos del periodo Posclásico entre Machaquila y la secuencia general del Sureste

\begin{tabular}{lllrrrr}
\hline \multicolumn{1}{c}{ Clases } & & Grupos & \multicolumn{3}{c}{ Machaquila } & Secuencia general \\
& & & n & \% & n & \% \\
\hline & & CLASES SIN ENGOBE & & & & \\
\hline Uaxactun Sin Engobe & Montículo & & 21 & 10,82 & 511 & 33,07 \\
Uakape & Chilo & & $86^{*}$ & 44,33 & 221 & 14,30 \\
Temax Burdo & Puluacax & & 1 & 0,52 & 63 & 4,08 \\
No Especificada & Patojo & & 2 & 1,03 & 209 & 13,53 \\
\hline & & CLASES CON ENGOBE & & & & \\
\hline Volador Engobe Dull & Paxcamán & & 18 & 9,28 & 377 & 24,40 \\
& Trapiche (engobe crema con pulimento) & $65^{* *}$ & 33,51 & 32 & 2,07 \\
Indeterminada & Indeterminado (tipo Internacional Mixteco) & 1 & 0,52 & 1 & 0,06 \\
(Otras) & & - & 194 & 131 & 8,48 \\
\hline TOTAL & & & 1.545 & \\
\hline
\end{tabular}

* Los porcentajes tan distintos obedecen aquí al hallazgo en la Estructura 34 de varios recipientes abotellados fracturados que se cuantificaron por fragmentos, mientras que en la clasificación de la secuencia se contemplaron como objetos individuales.

${ }_{* *}$ Esta aparente disfunción de cifras está asimismo en relación con un hallazgo de la Estructura 34, consistente en una serie de pequeñas ollas fracturadas que se cuantificaron por fragmentos, mientras que en la clasificación de la secuencia se contemplaron como objetos individuales.

contenido posclásico del Basurero PSP 40 tiene interés por la presencia, inequívoca aunque mínima, de un fragmento de Puluacax sin Engobe de la clase Temax Burdo, así como del definitorio tipo Paxcamán Rojo $(n=4)$. Por último cabe destacar dos casos especiales por sus características, que no por su número: un fragmento del tipo Mixteco Internacional en el Cuadrángulo y, en menor medida, dos del tipo Patojo Modelado (incensario) en la Estructura 27.

Ya en relación con la cerámica postclásica de la secuencia $(n=1.545)$, se han definido 11 clases cerámicas, aunque sólo cuatro de ellas tienen una mayor importancia cuantitativa (ver cuadro en Laporte 2007: 1744). En Machaquila sólo hacen su aparición seis de estas clases cerámicas, que serán las únicas que se contemplen en las comparaciones del Cuadro 8.

Para el material utilitario no engobado ( $\mathrm{n}=1.004 ; 65 \%)$, contamos con Uaxactun Sin Engobe ( $\mathrm{n}=511 ; 33,07 \%)$, Grupo Montículo; Uapake $(\mathrm{n}=221 ; 14,30 \%)$, Grupo Chilo; Temax Burdo ( $\mathrm{n}=63 ; 4,08 \%)$, Grupo Puluacax, y Clase No Especificada $(\mathrm{n}=$ 209; 13,53\%), Grupo Patojo (incensarios). Curiosamente en Machaquila existe presencia de las cuatro clases representadas en la secuencia general: Uaxactun sin Engobe $(\mathrm{n}=21)$, Uapake $(\mathrm{n}=86)$ (ver la nota del Cuadro 8), Temax Burdo $(\mathrm{n}=1)$ y la No Especificada que incluye los incensarios tipo Patojo Modelado $(n=2)$.

Como se aprecia en el Cuadro 8 , en la cerámica engobada $(n=490 ; 31,7 \%)$ destaca con gran diferencia la clase Volador Engobe Dull ( $\mathrm{n}=429 ; 27,8 \%)$, con los grupos Trapiche y Paxcaman, ya que el resto de las clases detectadas (Clemencia Pasta Crema, Vitzil Rojo-Naranja, Petén Lustroso y Pine Ridge Carbonatado -segunda en importancia: $\mathrm{n}=32 ; 2,1 \%-)$ apenas suponen todas juntas un $3,1 \%$ de la muestra total en la secuencia (ver cuadro en Laporte 2007: 1747). Machaquila sólo está representada por dos clases engobadas, la abrumadoramente mayoritaria Volador Engobe Dull (ver la nota del Cuadro 8) y la Indeterminada que se corresponde con el único fragmento de tipo Internacional Mixteco aparecido en la zona de prospección del Atlas. 
Ciertas circunstancias específicas hacen difícil un análisis comparativo como habíamos realizado en otros periodos y, en buena medida, obedecen al hecho de que el mayor número de materiales procede de objetos fracturados que estuvieron en uso (doméstico o ritual) en momentos muy puntuales, y que no necesariamente obedecen a permanencias continuadas de individuos, sino más bien a actuaciones esporádicas tal y como se comentaba anteriormente (ver nota 8 ).

\subsection{Contextos especiales: breve exposición y comentario}

Como habíamos avanzado, existen en Machaquila determinados contextos con fuertes implicaciones cerámicas que merecen tener un comentario específico: las concentraciones de material nominadas como basureros, de los que en Machaquila contamos con tres, y el recinto denominado, desde tiempos de I. Graham, como Cuadrilobulado.

Hace años, en la introducción de una reseña sobre una obra titulada The Ethnoarchaeology of refuse disposal (Staski y Sutro 1991), la autora de esta contribución realizaba el siguiente comentario: «Hay pocas pautas culturales que se den de forma tan recurrente y extendida dentro de todos los grupos humanos como la acumulación de desperdicios. La basura parece ser inherente no sólo al ser humano, sino a la naturaleza misma que tiene sus ciclos de creación y degradación [...] De lo que la naturaleza ofrece al hombre, éste toma lo que precisa, lo transforma -o no- en la medida de sus necesidades, hace uso de ello y, por último, desecha lo no utilizable. Continuamente el ciclo se repite: tomar, transformar, usar, desechar. Y produce una serie de patrones susceptibles de ser estudiados desde diferentes puntos de vista» (Iglesias 1993: 256257). La cultura maya no es una excepción, y de forma recurrente encontramos numerosos contextos arqueológicos consistentes en acumulaciones de materiales fracturados (cerámica, lítica, huesos, etc.) que parecen encajar en lo que en nuestra cultura actual denominamos basureros. Bien es cierto que no cualquier tipo de concentración de material fragmentado se corresponde necesariamente con esta pauta, que en nuestra lógica implica una acción de deshacernos de aquello que hemos dejado de necesitar, ya que existen acumulaciones de materiales que obedecen sin duda a otro tipo de comportamientos.

En Machaquila, siguiendo las pautas del Atlas Arqueológico, se han identificado como basureros ciertas concentraciones inhabituales, fundamentalmente de cerámica, aparecidas en nuestro caso en el nivel superficial. El número asciende a tres: PSP 40 (escalinata de acceso a la plaza E), PSP 41 (Estructura 10) y PSP 49 (Estructura 7/8, en el lado Este de los cuerpos del basamento).

\subsubsection{Basurero PSP 40}

Fue localizado en el espacio que media entre la parte oeste de la plataforma nominada como Estructura 30 y el inicio de la escalinata final que da acceso a la Plaza E a través de la conocida Estructura 32; posiblemente, dado el volumen de material rescatado, esta concentración se extendió, pegada al muro, en dirección sur hacia la Plaza C, en relación directa con la Estructura 31. 
Cuadro 9: Recuento y porcentajes cerámicos en el Basurero PSP 40

\begin{tabular}{|c|c|c|c|c|}
\hline Clase & Grupo & Tipo & $\mathbf{n}$ & $\%$ \\
\hline \multirow[t]{12}{*}{ Uaxactun sin Engobe } & \multirow[t]{9}{*}{ Cambio } & Cambio sin Engobe & 334 & 29,72 \\
\hline & & Cambio s/e n/d con Abundante Calcita & 27 & 2,40 \\
\hline & & Cambio s/e n/d con Mica & 6 & 0,53 \\
\hline & & Ciro Inciso & 5 & 0,44 \\
\hline & & Manteca Impreso & 1 & 0,09 \\
\hline & & Miseria Aplicado Cedral Aplicado (espiga) & 4 & 0,36 \\
\hline & & Chichicuil Baño Crema & 19 & 1,69 \\
\hline & & Chichicuil con Baño ND/ Brochazos Negros & 1 & 0,09 \\
\hline & & TOTAL GRUPO & 397 & 35,32 \\
\hline & \multirow[t]{2}{*}{ Encanto } & Encanto Estriado & 47 & 4,18 \\
\hline & & TOTAL GRUPO & 47 & 4,18 \\
\hline & \multicolumn{2}{|l|}{ TOTAL CLASE } & 444 & 39,50 \\
\hline \multirow[t]{33}{*}{ Petén Lustroso } & \multirow{2}{*}{ Harina } & Harina Crema & 1 & 0,09 \\
\hline & & TOTAL GRUPO & 1 & 0,09 \\
\hline & \multirow[t]{2}{*}{ Azote } & Azote Naranja & 3 & 0,27 \\
\hline & & TOTAL GRUPO & 3 & 0,27 \\
\hline & \multirow{10}{*}{ Tinaja } & Tinaja Rojo & 488 & 43,42 \\
\hline & & Tinaja Rojo Nanzal & 2 & 0,18 \\
\hline & & Tinaja Rojo Subin & 2 & 0,18 \\
\hline & & Camarón Inciso & 19 & 1,69 \\
\hline & & Camarón Inciso Corozal & 4 & 0,36 \\
\hline & & Tolla Acanalado & 4 & 0,36 \\
\hline & & Chaquiste Impreso o Impreso Sellado & 10 & 0,89 \\
\hline & & Chinja Impreso & 13 & 1,16 \\
\hline & & San Julio Modelado & 1 & 0,09 \\
\hline & & TOTAL GRUPO & 543 & 48,31 \\
\hline & \multirow[t]{4}{*}{ Remate } & Aduana Rojo & 7 & 0,62 \\
\hline & & Pantano Impreso & 12 & 1,07 \\
\hline & & Pantano Impreso Sellado & 5 & 0,44 \\
\hline & & TOTAL GRUPO & 24 & 2,14 \\
\hline & \multirow[t]{4}{*}{ Máquina } & Máquina Café & 15 & 1,33 \\
\hline & & Canoa Inciso & 12 & 1,07 \\
\hline & & Irasema Bícromo ND/ Brochazos Rojos & 3 & 0,27 \\
\hline & & TOTAL GRUPO & 30 & 2,67 \\
\hline & \multirow[t]{3}{*}{ Infierno } & Infierno Negro & 52 & 4,63 \\
\hline & & Carmelita Inciso & 3 & 0,27 \\
\hline & & TOTAL GRUPO & 55 & 4,89 \\
\hline & \multirow[t]{3}{*}{ Zacatal-Joyac } & Naranjal Rojo/Crema & 7 & 0,62 \\
\hline & & Juina Rojo-Ante & 1 & 0,09 \\
\hline & & TOTAL GRUPO & 8 & 0,71 \\
\hline & \multirow[t]{4}{*}{ Palmar-Danta } & Palmar Naranja Policromo & 5 & 0,44 \\
\hline & & Yuhactal Negro/Rojo & 1 & 0,09 \\
\hline & & Chantuori Negro/Naranja & 1 & 0,09 \\
\hline & & TOTAL GRUPO & 7 & 0,62 \\
\hline & TOTAL CLASE & & 671 & 59,70 \\
\hline \multirow[t]{3}{*}{ Ceniza Engobe Rojo } & \multirow[t]{2}{*}{ Belice } & Belice Rojo & 1 & 0,09 \\
\hline & & TOTAL GRUPO & 1 & 0,09 \\
\hline & \multicolumn{2}{|l|}{ TOTAL CLASE } & 1 & 0,09 \\
\hline \multirow[t]{3}{*}{ Naranja Fino } & Altar & Altar Naranja & 2 & 0,18 \\
\hline & & TOTAL GRUPO & 2 & 0,18 \\
\hline & \multicolumn{2}{|l|}{ TOTAL CLASE } & 2 & 0,18 \\
\hline
\end{tabular}


(continuación del Cuadro 9)

\begin{tabular}{|c|c|c|c|c|}
\hline \multirow[t]{3}{*}{ No especificada } & Daylight & Dayligth Naranja & 1 & 0,09 \\
\hline & \multirow{2}{*}{\multicolumn{2}{|c|}{ TOtaL CLASE }} & 1 & 0,09 \\
\hline & & & 1 & 0,09 \\
\hline \multicolumn{5}{|c|}{ POSTCLÁSICO } \\
\hline \multirow[t]{3}{*}{ Temax Burdo } & Puluacax & Puluacax sin Engobe & 1 & 0,09 \\
\hline & & TOTAL GRUPO & 1 & 0,09 \\
\hline & TOTAL CLASE & & 1 & 0,09 \\
\hline \multirow[t]{3}{*}{ Volador Engobe Dull } & Paxcaman & Paxcaman Rojo & 4 & 0,36 \\
\hline & & TOTAL GRUPO & 4 & 0,36 \\
\hline & TOTAL CLASE & & 4 & 0,36 \\
\hline TOTAL & & & 24 & \\
\hline
\end{tabular}

Siguiendo las pautas de otras zonas del sitio, vemos en el Cuadro 9 que la cerámica engobada $(60,49 \%)$ supera con creces a la utilitaria sin engobe $(39,50 \%)$. El número de clases presente en este basurero es de siete, dos de ellas de cerámica postclásica, subdivididas en 15 grupos y 38 tipos. Entre los grupos destaca la variabilidad de Tinaja $(48,31 \%)$, con nueve tipos, seguido de Cambio $(35,32 \%)$ con ocho, y Máquina $(2,67 \%)$, Remate $(2,14 \%)$ y Palmar-Danta $(0,62 \%)$ con tres, aunque en porcentaje es el Grupo Infierno el que destaca en tercer lugar (4,89\%).

A nivel de tipos, las diferencias se mantienen y es el engobado Tinaja Rojo $(43,42 \%)$ el que encabeza la lista seguido de Cambio sin Engobe (29,72\%) y, a considerable distancia, Infierno Negro (4,63\%), Encanto Estriado (4,18\%) y Cambio s/e n/d con Abundante Calcita (2,40\%). La relevancia de ciertos tipos minoritarios como los tres pertenecientes al grupo Remate (2,14\%), Belice Rojo, Altar Naranja o Dayligth Naranja está no tanto en sus porcentajes como en su presencia, que sitúan a Machaquila en una más que aceptable dinámica de intercambio con diferentes áreas de importancia. Esta misma relevancia se aplica a la testimonial representación para el Postclásico de Puluacax sin Engobe (0,09\%) y Paxcaman Rojo (0,36\%).

\subsubsection{Basurero PSP 41}

Está localizado sobre la parte media y meridional de la Estructura 10, en el lado Este de la Plaza F. Al hallarse en superficie y dada la aparición de cerámicas diagnósticas, está fechado para el Clásico Terminal. Dentro de esta concentración ( $\mathrm{n}=1.619)$, están presentes cinco clases, con 13 grupos y 27 tipos cerámicos (Cuadro 10). De las clases, la Petén Lustroso tiene una presencia mayoritaria $(63,74 \%)$ frente a Uaxactún Sin Engobe (34,28\%), Ceniza-Engobe Rojo $(1,30 \%)$ y Naranja Fina $(0,62 \%)$. Al menos dos de los grupos (Cambio y Tinaja) tienen una amplia representación de tipos, aunque destacan con diferencia Tinaja Rojo $(49,91 \%)$ y Cambio sin Engobe $(31,62 \%)$, seguidos a gran distancia por Infierno Negro $(5,87 \%)$, Chinja Impreso $(3,03 \%)$, Chichicuil Baño Crema $(1,30 \%)$ y Belice Rojo $(1,24 \%)$ entre otros. Es de interés la aparición, aunque mínima, en el recuento general del basurero de diez fragmentos $(0,62 \%)$ de la Clase Naranja Fina, que determina la cronología del basurero, así como la anecdótica presencia de un fragmento Flor Crema del Preclásico Tardío. 
Cuadro 10: Recuento y porcentajes cerámicos en el Basurero PSP 41

\begin{tabular}{|c|c|c|c|c|}
\hline Clase & Grupo & Tipo & n & $\%$ \\
\hline \multirow[t]{9}{*}{ Uaxactun sin Engobe } & Cambio & Cambio sin Engobe & 512 & 31,62 \\
\hline & & Cambio s/e con Abundante Calcita & 6 & 0,37 \\
\hline & & Manteca Impreso & 1 & 0,06 \\
\hline & & Pedregal Aplicado Inciso & 1 & 0,06 \\
\hline & & Chichicuil Baño Crema & 21 & 1,30 \\
\hline & & TOTAL GRUPO & 541 & 33,42 \\
\hline & Encanto & Encanto Estriado & 14 & 0,86 \\
\hline & & TOTAL GRUPO & 14 & 0,86 \\
\hline & TOTAL CLASE & & 555 & 34,28 \\
\hline \multirow[t]{24}{*}{ Petén Lustroso } & Harina & Harina Crema & 2 & 0,12 \\
\hline & & Corrales Inciso & 1 & 0,06 \\
\hline & & TOTAL GRUPO & 3 & 0,19 \\
\hline & Azote & Azote Naranja & 5 & 0,31 \\
\hline & & TOTAL GRUPO & 5 & 0,31 \\
\hline & Tinaja & Tinaja Rojo & 808 & 49,91 \\
\hline & & Camarón Inciso & 7 & 0,43 \\
\hline & & Camarón Inciso Corozal & 7 & 0,43 \\
\hline & & Chaquiste Impreso Sellado & 9 & 0,56 \\
\hline & & Chinja Impreso & 49 & 3,03 \\
\hline & & Portia Gubiado-Inciso & 5 & 0,31 \\
\hline & & TOTAL GRUPO & 885 & 54,66 \\
\hline & Remate & Pantano Impreso & 12 & 0,74 \\
\hline & & Pantano Impreso Sellado & 9 & 0,56 \\
\hline & & Ones Impreso & 1 & 0,06 \\
\hline & & TOTAL GRUPO & 22 & 1,36 \\
\hline & Máquina & Máquina Café & 14 & 0,86 \\
\hline & & TOTAL GRUPO & 14 & 0,86 \\
\hline & Infierno & Infierno Negro & 95 & 5,87 \\
\hline & & Carmelita Inciso & 6 & 0,37 \\
\hline & & TOTAL GRUPO & 101 & 6,24 \\
\hline & Zacatal-Joyac & Naranjal Rojo/Crema & 2 & 0,12 \\
\hline & & TOTAL GRUPO & 2 & 0,12 \\
\hline & TOTAL CLASE & & 1.032 & 63,74 \\
\hline \multirow[t]{4}{*}{ Ceniza-Engobe Rojo } & Belice & Belice Rojo & 20 & 1,24 \\
\hline & & Platón Punzonado - Inciso & 1 & 0,06 \\
\hline & & TOTAL GRUPO & 21 & 1,30 \\
\hline & TOTAL CLASE & & 21 & 1,30 \\
\hline \multirow[t]{5}{*}{ Naranja Fino } & Altar & Altar Naranja & 6 & 0,37 \\
\hline & & TOTAL GRUPO & 6 & 0,37 \\
\hline & Tres Naciones & Tres Naciones Gris & 4 & 0,25 \\
\hline & & TOTAL GRUPO & 4 & 0,25 \\
\hline & TOTAL CLASE & & 10 & 0,62 \\
\hline & & PRECLÁSICO TARDÍO & & \\
\hline \multirow{3}{*}{ Paso Caballo Ceroso } & Flor & Flor Crema & 1 & 0,06 \\
\hline & & TOTAL GRUPO & 1 & 0,06 \\
\hline & TOTAL CLASE & & 1 & 0,06 \\
\hline TOTAL & & & 1.619 & \\
\hline
\end{tabular}




\subsubsection{Basurero PSP 49}

En los cuerpos intermedios del lado Este de la Estructura abovedada 7/8, que comparte el espacio norte de la Plaza G y el sur de la Plaza F, se halló una concentración catalogada como Basurero PSP 49 (Cuadro 11) en el que, a diferencia de los dos casos anteriores, se aprecia una menor variabilidad (4 clases, 11 grupos, 22 tipos). Ostenta asimismo este basurero una clara superioridad de la cerámica utilitaria (Clase Uaxactún sin Engobe, 63,55\%) mayoritariamente con forma de grandes cántaros del tipo Cambio sin engobe (57,45\%) y Encanto Estriado (4,31\%), frente a la cerámica engo-

Cuadro 11: Recuento y porcentajes cerámicos en el Basurero PSP 49

\begin{tabular}{|c|c|c|c|c|}
\hline Clase & Grupo & Tipo & $\mathbf{n}$ & $\%$ \\
\hline \multirow[t]{8}{*}{ Uaxactun sin Engobe } & \multirow[t]{5}{*}{ Cambio } & Cambio sin Engobe & 320 & 57,45 \\
\hline & & Cambio s/e $\mathrm{n} / \mathrm{d}$ con Abundante Calcita & 7 & 1,26 \\
\hline & & Ciro Inciso & 1 & 0,18 \\
\hline & & Pijije Calado & 2 & 0,36 \\
\hline & & TOTAL GRUPO & 330 & 59,25 \\
\hline & \multirow[t]{2}{*}{ Encanto } & Encanto Estriado & 24 & 4,31 \\
\hline & & TOTAL GRUPO & 24 & 4,31 \\
\hline & \multicolumn{2}{|l|}{ Total CLASE } & 354 & 63,55 \\
\hline \multirow[t]{23}{*}{ Petén Lustroso } & \multirow[t]{3}{*}{ Azote } & Azote Naranja & 11 & 1,97 \\
\hline & & Torres Inciso & 2 & 0,36 \\
\hline & & TOTAL GRUPO & 13 & 2,33 \\
\hline & \multirow[t]{7}{*}{ Tinaja } & Tinaja Rojo & 119 & 21,36 \\
\hline & & Tinaja Rojo Nanzal & 1 & 0,18 \\
\hline & & Tinaja Rojo Acacia & 1 & 0,18 \\
\hline & & Camarón Inciso & 19 & 3,41 \\
\hline & & Chaquiste Impreso-Sellado & 3 & 0,54 \\
\hline & & Chinja Impreso & 3 & 0,54 \\
\hline & & TOTAL GRUPO & 146 & 26,21 \\
\hline & \multirow[t]{3}{*}{ Remate } & Pantano Impreso & 3 & 0,54 \\
\hline & & Pantano Impreso-Sellado & 14 & 2,51 \\
\hline & & TOTAL GRUPO & 17 & 3,05 \\
\hline & \multirow[t]{3}{*}{ Máquina } & Máquina Café & 8 & 1,44 \\
\hline & & Canoa Inciso & 6 & 1,08 \\
\hline & & TOTAL GRUPO & 14 & 2,51 \\
\hline & \multirow{2}{*}{ Infierno } & Infierno Negro & 2 & 0,36 \\
\hline & & TOTAL GRUPO & 2 & 0,36 \\
\hline & \multirow[t]{2}{*}{ Zacatal-Joyac } & Chinos Negro-Crema & 1 & 0,18 \\
\hline & & TOTAL GRUPO & 1 & 0,18 \\
\hline & \multirow[t]{2}{*}{ Palmar-Danta } & Leona Rojo-Naranja & 4 & 0,72 \\
\hline & & TOTAL GRUPO & 4 & 0,72 \\
\hline & TOTAL CLASE & & 197 & 35,37 \\
\hline \multirow[t]{3}{*}{ No Especificada } & \multirow[t]{2}{*}{ Daylight } & Daylight Naranja & 5 & 0,90 \\
\hline & & TOTAL GRUPO & 5 & 0,90 \\
\hline & \multicolumn{2}{|l|}{ TOTAL CLASE } & 5 & 0,90 \\
\hline & & POSTCLÁSICO & & \\
\hline \multirow[t]{3}{*}{ Volador Engobe Dull } & \multirow[t]{2}{*}{ Paxcaman } & Paxcaman Rojo & 1 & 0,18 \\
\hline & & TOTAL GRUPO & 1 & 0,18 \\
\hline & TOTAL CLASE & & 1 & 0,18 \\
\hline TOTAL & & & 557 & \\
\hline
\end{tabular}


bada $(36,45 \%)$ en la que destaca Petén Lustroso $(35,37 \%)$, en la que destacan sobre el resto los tipos Tinaja Rojo (21,36\%), Camarón Inciso (3,41\%), Pantano ImpresoSellado $(2,51 \%)$. También hay que reseñar un único fragmento del tipo Paxcamán Rojo para el Postclásico.

La presencia de los grandes cántaros fracturados hacen pensar en un contexto mezclado en el que, además de basurero, existe la presencia de cerámicas no necesariamente desechadas, sino colocadas estratégica o ritualmente en superficie en momentos previos al abandono de la Estructura 7/8 o en relación con él. En un acto de abandono, las piezas cerámicas de gran tamaño, y por ello más fácilmente fracturables, son usualmente dejadas en su contexto de uso, sin que ello suponga una pauta ritual, aunque en ocasiones puede ser difícil diferenciar la intencionalidad de dicho acto.

\subsubsection{Cuadrilobulado}

Este peculiar rasgo cultural, ya descrito en aportaciones precedentes de este dossier, es de singular importancia por su colocación -en el espacio central de la Plaza A-y por su significación ritual. En consonancia con su excepcionalidad, contamos con una buena cantidad de material cerámico, en relación con el cual, y en un informe anterior (ver Lacadena 2005), se resaltaban tres características: su gran fragmentación, su alto grado de remoción y superficies muy erosionadas y quemadas 9 . A pesar de ello ha sido posible clasificar un total de 9.556 fragmentos, correspondientes a un buen número de los tipos cerámicos conocidos para las esferas Tepeu 1, 2 y 3 (Clásico Tardío y Terminal).

Este volumen de material procede de la excavación de aproximadamente 1/3 del cuadrilobulado (la profundidad de la matriz excavable no va más allá de los $40 \mathrm{~cm}$ ), lo que significa una concentración de material considerable. Aunque la cantidad de los tipos que convencionalmente se califican como incensarios no parecería excesivamente elevada $(n=578,6,04 \%)^{10}$, sí lo es en comparación con cualquier otro contexto trabajado en Machaquila, y no sólo en relación con estas vasija de uso ritual; de hecho, si bien cuenta para un volumen de cerámica tan relativamente importante con sólo cinco clases diferentes - una de ellas con 12 fragmentos del Preclásico Tardío y otra representada por un único fragmento definitorio del Clásico Terminal-y 13 grupos, es en el capítulo de tipos cerámicos donde se puede apreciar una inusitada variedad: 53 tipos diferentes (Cuadro 12). Sin duda ello le confiere un carácter de excepcionalidad que no tenemos en ningún otro contexto excavado en la ciudad.

\footnotetext{
${ }^{9}$ Como bien explica Lacadena (2005), estas características pueden deberse a diferentes causas, fundamentalmente por haber sido un espacio abierto y que por ello sufrió de forma continuada las inclemencias del clima tropical y un crecimiento de manto vegetal continuado. También examina explicaciones diferentes para la fuerte presencia de zonas quemadas, ya que tenemos constancia de una, corta pero reciente, utilización de las plazas del sitio como milpas, pero ninguna otra presenta esos excesos de quemazón, por lo que las mayores posibilidades de explicación siguen siendo las de rituales antiguos.

${ }_{10}$ Hay que tener en cuenta que se clasifican como tales sólo fragmentos plenamente reconocibles o significativos, pero que un fuerte porcentaje de los fragmentos que le corresponderían debe estar engrosando las cifras de Cambio sin Engobe en general.
} 
Cuadro 12: Recuento y porcentajes cerámicos en el Cuadrilobulado de la Plaza A

\begin{tabular}{|c|c|c|c|c|}
\hline Clase & Grupo & Tipo & $\mathbf{n}$ & $\%$ \\
\hline \multirow[t]{16}{*}{ Uaxactun sin Engobe } & \multirow[t]{13}{*}{ Cambio } & Cambio Sin Engobe: Cambio & 2.161 & 22,61 \\
\hline & & Cambio Sin Engobe: ND/ Abundante Calcita & 119 & 1,25 \\
\hline & & ${ }^{* *}$ Ciro Inciso: Ciro & 6 & 0,06 \\
\hline & & ${ }^{{ }^{* *} \text { Manteca Impreso: Manteca (superficie) }}$ & 1 & 0,01 \\
\hline & & ${ }^{* *}$ Manteca Impreso: ND/En Filete & 1 & 0,01 \\
\hline & & ${ }^{* *}$ Miseria Aplicado: Miseria & 2 & 0,02 \\
\hline & & ${ }^{{ }^{* *} \text { Miseria Aplicado: Cedral (espiga) }}$ & 268 & 2,80 \\
\hline & & ${ }^{* *}$ Pedregal Modelado: Pedregal & 209 & 2,19 \\
\hline & & ${ }^{* *}$ Pedregal Modelado: ND/Aplicado & 83 & 0,87 \\
\hline & & ${ }^{* *}$ Pedregal Modelado: ND/Aplicado-Inciso & 1 & 0,01 \\
\hline & & ${ }^{*}$ Pijije Calado: Pijije & 7 & 0,07 \\
\hline & & Chichicuil Con Baño: Chichicuil (baño crema) & 8 & 0,08 \\
\hline & & TOTAL GRUPO & 2.866 & 29,99 \\
\hline & \multirow[t]{2}{*}{ Encanto } & Encanto Estriado: Estriado & 436 & 4,56 \\
\hline & & TOTAL GRUPO & 436 & 4,56 \\
\hline & TOTAL CLASE & & 3.302 & 34,55 \\
\hline \multirow[t]{35}{*}{ Petén Lustroso } & \multirow[t]{2}{*}{ Harina } & Harina Crema: Harina & 23 & 0,24 \\
\hline & & TOTAL GRUPO & 23 & 0,24 \\
\hline & \multirow[t]{3}{*}{ Azote } & Azote Naranja: Azote & 25 & 0,26 \\
\hline & & Torres Inciso: Inciso & 1 & 0,01 \\
\hline & & TOTAL GRUPO & 26 & 0,27 \\
\hline & \multirow[t]{18}{*}{ Tinaja } & Tinaja Rojo: Tinaja & 4.803 & 50,26 \\
\hline & & Tinaja Rojo: Nanzal & 34 & 0,36 \\
\hline & & Tinaja Rojo: ND/ Pasta Micácea & 1 & 0,01 \\
\hline & & Tinaja Rojo: Subin & 308 & 3,22 \\
\hline & & Tinaja Rojo: Calderitas (engobe escamoso) & 2 & 0,02 \\
\hline & & Camarón Inciso: Camarón & 22 & 0,23 \\
\hline & & Camarón Inciso: Corozal & 9 & 0,09 \\
\hline & & Chaquiste Impreso: Chaquiste & 97 & 1,02 \\
\hline & & Chaquiste Impreso: ND/Sellado & 20 & 0,21 \\
\hline & & Pantano Impreso: Pantano & 14 & 0,15 \\
\hline & & Pantano Impreso: Sellado & 6 & 0,06 \\
\hline & & Chinjá Impreso: Chinjá & 16 & 0,17 \\
\hline & & Tigrán Estriado: Tigrán & 3 & 0,03 \\
\hline & & Zelmira Aplicado: Zelmira & 1 & 0,01 \\
\hline & & San Julio Modelado: San Julio & 1 & 0,01 \\
\hline & & Portia Guabiado-Inciso: Portia & 3 & 0,03 \\
\hline & & Zopilote Bícromo: Zopilote Manchado & 6 & 0,06 \\
\hline & & TOTAL GRUPO & 5.346 & 55,94 \\
\hline & \multirow[t]{3}{*}{ Máquina } & Máquina Café: Máquina & 89 & 0,93 \\
\hline & & Canoa Inciso: Canoa & 20 & 0,21 \\
\hline & & TOTAL GRUPO & 109 & 1,14 \\
\hline & \multirow[t]{6}{*}{ Infierno } & Infierno Negro: Infierno & 617 & 6,46 \\
\hline & & Infierno Negro: Carmelita & 4 & 0,04 \\
\hline & & Infierno negro: ND/Acanalado-Inciso & 6 & 0,06 \\
\hline & & Chilar Acanalado: Chilar & 4 & 0,04 \\
\hline & & Toro Gubiado-Inciso: Toro & 6 & 0,06 \\
\hline & & TOTAL GRUPO & 637 & 6,67 \\
\hline & \multirow[t]{3}{*}{ Zacatal-Joyac } & Naranjal Rojo/Crema: Naranjal & 7 & 0,07 \\
\hline & & Chinos Negro/Crema: Chinos & 2 & 0,02 \\
\hline & & Zacatal Crema Polícromo: Zacatal & 11 & 0,12 \\
\hline
\end{tabular}


(continuación del Cuadro 12)

\begin{tabular}{|c|c|c|c|c|}
\hline & & Juiná Rojo/Ante: Juiná & 13 & 0,14 \\
\hline & & Paixbán Ante Polícromo: Paixbán & 2 & 0,02 \\
\hline & & TOTAL GRUPO & 35 & 0,37 \\
\hline & Palmar-Danta & Palmar Naranja Policromo: Palmar & 38 & 0,40 \\
\hline & & Yuhactal Negro/Rojo: Yuhactal & 5 & 0,05 \\
\hline & & TOTAL GRUPO & 43 & 0,45 \\
\hline & TOTAL CLASE & & 6.219 & 65,08 \\
\hline Ceniza-Engobe Rojo & Belice & Belice Rojo: Belice & 22 & 0,23 \\
\hline & & TOTAL GRUPO & 22 & 0,23 \\
\hline & TOTAL CLASE & & 22 & 0,23 \\
\hline & & PRECLÁSICO TARDÍO & & \\
\hline Paso Caballos Ceroso & Flor & Flor Crema: Flor & 8 & 0,08 \\
\hline & & Flor Crema: Luciano & 2 & 0,02 \\
\hline & & TOTAL GRUPO & 10 & 0,10 \\
\hline & Sierra & Sierra Rojo: Sierra & 1 & 0,01 \\
\hline & & Laguna Verde Inciso: Sereque & 1 & 0,01 \\
\hline & & TOTAL GRUPO & 2 & 0,02 \\
\hline & TOTAL CLASE & & 12 & 0,13 \\
\hline & & CLÁSICO TERMINAL & & \\
\hline Uaxactun sin Engobe & Cambio & $\begin{array}{l}\text { Pedregal Modelado: Bocut Modelado } \\
\text { (mango con garra) }\end{array}$ & 1 & 0,01 \\
\hline & & TOTAL GRUPO & 1 & 0,01 \\
\hline & TOTAL CLASE & & 1 & 0,01 \\
\hline TOTAL & & & 9.556 & \\
\hline
\end{tabular}

Nota: los tipos precedidos con dos asteriscos indican que han sido calificados como incensarios.

En un rápido análisis de las cifras sobresale, al igual que en el resto de la ciudad, la Clase Peten Lustroso (65,08\%); dentro de ella el Grupo Tinaja (55,94\%) y, a su vez, el Tipo Tinaja Rojo: Tinaja (50,26\%); aun estando presentes el resto de grupos monocromos convencionales (Harina, Azote, Máquina e Infierno), el segundo más significativo sería el de Infierno (6,67\%). Es de interés referirse a la presencia $(0,82 \%)$ - a pesar de su necesaria mala conservación- de cerámicas bicromas y policromas. El tipo Belice Rojo (0,23\%), Clase Ceniza-Engobe Rojo, es la única presencia de material menos local y en un porcentaje muy reducido.

El resto de los tipos de la Clase Uaxactun sin Engobe -los no vinculados a incensarios- cuenta con el 28,51\%, con una mayoría habitual del tipo Cambio sin Engobe $(22,61 \%)$, frente a Encanto Estriado (4,56\%). A la vista de las formas presentes, de las que casi $2 / 3$ pertenecen a cerámicas engobadas de servir, mientras que los tipos no engobados de cocinar, contener y/o transportar líquidos suponen el otro tercio, cabe inferir que estamos ante un claro espacio ritual donde no sólo se realizaban ofrendas de copal a dioses y ancestros, sino donde debió tener singular importancia tanto la manipulación como la ingesta de alimentos, posiblemente dentro de los mismos rituales ${ }^{11}$.

Otro aspecto a destacar es su cronología, ya que, de forma casi total, el material pertenece a tipos cerámicos indiferenciados para el Clásico Tardío y Clásico Terminal

11 Aunque reducida, cabe también apuntar la presencia de otros objetos cerámicos tales como cajas de cerámica (Lacadena 2005, Figura 2.10, Fotos 173 a 175), instrumentos musicales, y figurillas (Fotos 170 y 171). 
(salvo un fragmento de incensario de mango-garra, muy definitorio del Terminal, tipo Pedregal Modelado: Bocut Modelado), sin ninguna aparición del Clásico Temprano y apenas anecdótica $(\mathrm{n}=12,0,13 \%)$ para el Preclásico Tardío. La pauta de presencia/ausencia y los porcentajes de determinados tipos cerámicos -en relación con la secuencia general del Atlas- inducen a pensar que, tanto la construcción como el uso del cuadrilobulado de la Plaza A, tuvo lugar en un momento de transición, posiblemente a comienzos de Clásico Terminal, a lo largo del siglo IX d.C. (para la cronología del Cuadrilobulado ver la argumentación completa en Lacadena 2005; para su importancia iconográfica, ver Lacadena en este dossier).

\section{La historia que nos cuenta la cerámica: reflexiones finales}

Está fuera de todo cuestionamiento que, dentro del registro arqueológico, la cerámica es parte esencial a la hora de reconstruir una cronología y de caracterizar los desarrollos culturales tanto a niveles específicos, ya sea de un pequeño sitio o una gran ciudad, como a instancias más amplias de regiones geográficas o áreas culturales. Bien es cierto que, según las características del lugar bajo estudio, la cerámica, y en general todos los restos muebles, pueden tener una mayor o menor eficacia o importancia y, en unos casos, servir para resolver problemas de orden tanto contextual como cronológico, mientras que en otros sólo serán idóneos -y no es poco- como constatación de las inferencias aportadas por rasgos arquitectónicos, iconográficos, epigráficos, etc.

Una cultura tan compleja y llena de matices regionales como es la maya refleja plenamente esa problemática en su cerámica; de ahí que, a pesar de contar con una herramienta tan buena como el sistema tipo-variedad («ayudado» en las últimas décadas por la introducción de análisis complementarios de tipo modal o estadístico), necesite aún de mucho trabajo para lograr establecer más secuencias cerámicas que contribuyan a plasmar una perspectiva general, que no deje aisladas aquellas regionales, ya que en estos regionalismos está asimismo la clave de los desarrollos socioeconómicos de esta cultura.

En el caso de Machaquila, no cabe esperar, ni era ese el objetivo, que su cerámica pueda solventar algunos de los múltiples problemas, tanto de tipo metodológico como cronológico, que están presentes en las Tierras Bajas Centrales, y ni siquiera dentro de la secuencia del Atlas Arqueológico de Guatemala. Nuestra cerámica, a falta de un análisis más preciso en relación con sus formas, nos indica cómo fue el acontecer ordinario y extraordinario de las gentes que habitaron la ciudad durante al menos 200 años, y constata una cronología atada a los cambios arquitectónicos -técnicos y estéticos-y a la presencia de material glífico en sus más que apreciables estelas y en otras de ciudades relacionadas.

Hay que partir del hecho que la fundación de Machaquila (Ciudad y Lacadena 2006) responde a un fenómeno diferente al de los referentes que puede tener en su misma zona; no estamos ante un asentamiento antiguo, sino ante un acto de voluntad regia específico que, muy posiblemente, obedece a imperativos estratégicos de seguridad. Las fuentes epigráficas señalan que las élites estarían plenamente asentadas (con ca- 
Cuadro 13: Comparación entre los porcentajes de aparición de cerámicas engobadas y no engobadas para el Clásico Tardío y Terminal

\begin{tabular}{lcccc}
\hline \multicolumn{1}{c}{ Periodos } & \multicolumn{2}{c}{ Cerámica utilitaria, sin engobe } & \multicolumn{2}{c}{ Cerámica engobada } \\
& Machaquila & Secuencia general & Machaquila & Secuencia general \\
\hline Clásico Tardío & $26,65 \%$ & $56,60 \%$ & $73,33 \%$ & $43,70 \%$ \\
Clásico Terminal & $28,85 \%$ & $46,38 \%$ & $71,04 \%$ & $53,45 \%$ \\
\hline
\end{tabular}

pacidad de erigir estelas talladas) para el 711 d.C. ${ }^{12}$, por lo que habrían llegado a la zona en las últimas décadas del siglo VII. Las pequeñas cantidades halladas de material del Preclásico Tardío y Clásico Temprano aparentemente nos informan de que no existió un poblamiento formal anterior y esos fragmentos pueden obedecer - ¿por qué no?a su presencia en el ajuar de los primeros pobladores, heredado, conservado y mantenido hasta el Clásico Tardío, cuando el poblamiento es efectivo, ya que está claramente atado a la arquitectura.

Machaquila no fue una ciudad de servicios al uso; posee un área habitacional periférica extraordinariamente reducida para lo que se espera de una urbe que mantiene durante dos centurias una población elitista, capaz de erigir estelas como muestra de su estatus regional. Los porcentajes de cerámica rescatada, tanto para el Clásico Tardío como para el Terminal, presentan fuertes desequilibrios entre las cerámicas utilitarias (cocina y transporte) y las engobadas (servicio), como se aprecia en el Cuadro 13. Podríamos decir de forma general que, entre su población, hubo más gente que era servida que aquella que se dedicaba a cocinar y servir; y ello se ve no sólo en las excavaciones generales, sino en los propios basureros y en un contexto ritual como es el Cuadrilobulado.

Machaquila tampoco fue una creadora de rasgos culturales, y a imagen de como debió haberse desarrollado en su desconocida localización originaria antes de la tardía refundación, se limitó a seguir y usar los modelos que estaban en vigencia en esa época en una buena parte de las Tierras Bajas, eso sí, aplicándolos a sus circunstancias específicas, como el hecho de estar poblada mayoritariamente por clases nobles y, así correspondía a su rango desde antiguo, estar en el circuito de ciudades receptoras de influencias suprarregionales, como se ve en la presencia de la cerámica Naranja Fina, o rasgos arquitectónicos propios de mayas septentrionales, como la piedra de revestimiento o los mosaicos de piedra decorando las fachadas de algunas de sus estructuras.

Cabe por último recordar que esta secuencia tiene una ausencia importante: la de los contextos funerarios, que aún no han sido determinados y que podrán, en algún momento, clarificar cuanto menos las diferentes relaciones que las élites machaquileñas mantuvieron con sus homónimos sociales de otras zonas.

En relación con las cerámicas pertenecientes al periodo Posclásico, su aparición nos remite especialmente a tres contextos, coincidentes con estructuras que son poseedoras de rasgos estéticos especiales y por ello, quizás, merecedoras de visitas de veneración una vez abandonada la ciudad: la Estructura 4 con su banca jeroglífica, la Estructura

12 Es el año de la primera estela fechada en Machaquila, lo que no es óbice para que años antes se hubiera producido ya el traslado (Ciudad y Lacadena 2006: 166-173). 
7/8 con los mascarones que recrean la Montaña de las Flores (Lacadena e Iglesias 2006) y la Estructura 34 con su fachada norte cuajada de elementos estucados.

Como se puede apreciar por esta aportación, la historia de Machaquila no la cuentan básicamente sus cerámicas, sino su arquitectura y escultura, que al seguir unas dinámicas de desarrollo muy similares en varios aspectos a los de sus contemporáneos de las Tierras Bajas, nos hurta, por ahora, conocer la localización primigenia de sus fundadores, de aquellos que fueron capaces de reinventarse en un espacio diferente, seguramente similar a nivel ecológico, pero lejos de quienes la amenazaban. Y gracias a ello pudo alargar su historia a través de una vida relativamente apacible por otros 200 años. Tuvieron que pasar muchos siglos antes de que arqueólogos, campesinos y saqueadores llegaran a romper el ruidoso silencio que caracteriza los entornos selváticos como el de Machaquila. Siempre estaremos agradecidos a Juan Pedro Laporte, que nos proporcionó el privilegio de trabajar en esta emblemática ciudad formando parte de su equipo.

\section{Referencias bibliográficas}

ADAMS, Richard E.W.

1971 The Ceramics of Altar de Sacrificios. Papers of the Peabody Museum of Archaeology and Ethnology, vol. 63 (1). Cambridge: Harvard University.

ADAms, Richard E.W. y Aubrey S. TRIK

1961 «Temple 1 (Str. 5D-1): Post-Constructional Activities», en Tikal Reports 7, pp. 113148. Filadelfia: University Museum, University of Pennsylvania.

Atlas Arqueológico de Guatemala

2008 Registro de sitios arqueológicos del sureste y centro-oeste de Petén, 1987-2008. Serie Monografías. Guatemala: Atlas Arqueológico de Guatemala. Documento electrónico, <http://www.atlasarqueologico.com/monografias.php?idm=11>, con acceso el 2/11/2010.

CHASE, Arlen F. y Diane Z. CHASE

2004 «Hermeneutics, Transitions, and Transformations in Classic to Postclassic Maya Society», en The Terminal Classic in the Maya Lowlands. Collapse, Transition, and Transformation, Arthur A. Demarest, Prudence M. Rice y Donald S. Rice eds., pp. 12-27. Colorado: University Press of Colorado.

Ciudad Ruiz, Andrés y Alfonso lacadena García-Gallo

2006 «La fundación de Machaquilá, Petén, en el Clásico Tardío maya», en Nuevas ciudades, nuevas patrias. Fundación y relocalización de ciudades en Mesoamérica y el Mediterráneo Antiguo, $\mathrm{M}^{\mathrm{a}}$ Josefa Iglesias, Rogelio Valencia y Andrés Ciudad, eds., pp. 149-180. Madrid: Sociedad Española de Estudios Mayas.

Culbert, T. Patrick

1973 «The Maya Downfall at Tikal», en The Classic Maya Collapse, T. Patrick Culbert, ed., pp. 63-92. Albuquerque: University of New Mexico Press.

Escobedo, Héctor L., María Teresa Robles y Lori E. WRight

1992 «El Duende: Excavaciones en un sector ceremonial y habitacional del sitio de Dos Pilas», en IV Simposio de Investigaciones Arqueológicas en Guatemala, 1990, Juan 
Pedro Laporte, Héctor Escobedo y Sandra Brady, eds., pp. 131-138. Guatemala: Museo Nacional de Arqueología y Etnología.

FOIAS, Antonia

1996 Changing Ceramic Production and Exchange Systems and the Classic Maya Collapse in the Petexbatun Region. Tesis Doctoral. Nashville: Vanderbilt University,

Forné, Mélanie

2005 La chronologie céramique de La Joyanca, nord-ouest du Petén, Guatemala. Tesis Doctoral. París: Université Paris I-Panthéon-Sorbonne U.F.R. Histoire de l'Art et Archéologie.

FORSYTH, Donald W.

1998 «Cambios y continuidades durante el Clásico Tardío y Terminal en las Tierras Bajas del Sur», en Investigadores de la Cultura Maya 6, pp. 63-80. Campeche: Universidad Autónoma de Campeche.

2005 «A Survey of Terminal Classic Ceramic Complexes and their Socioeconomic Implications», en Geographies of Power: Understanding the Nature of Terminal Classic Pottery in the Maya Lowlands, Sandra López Varela y Antonia Foias, eds., pp. 7-22. Oxford: BAR International Series 1447.

Hansen, Richard D., Mitchell Marken, Donald Forsyth y Bernard Hermes

1993 «Estudios de PRIANPEG en el lago Petén Itza: resultados preliminares». Ponencia presentada en el VII Simposio de Investigaciones Arqueológicas en Guatemala, 1993. Guatemala: Museo Nacional de Arqueología y Etnología.

Hermes Cifuentes, Bernard y Raúl Noriega

1998 «El periodo Postclásico en el área de la laguna Yaxha: Una visión desde Topoxte», en XI Simposio de Investigaciones Arqueológicas en Guatemala, 1997, Juan Pedro Laporte y Héctor Escobedo, eds. pp. 755-778. Guatemala: Museo Nacional de Arqueología y Etnología.

Houston, Stephen D., Héctor L. EscoBedo y Mark CHILD

1999 «Al filo de la navaja: Resultados de la segunda temporada del Proyecto Arqueológico Piedras Negras», en XII Simposio de Investigaciones Arqueológicas en Guatemala, 1998, Juan Pedro Laporte, Héctor Escobedo y Ana Claudia de Suasnávar, eds., pp. 373-392. Guatemala: Museo Nacional de Arqueología y Etnología.

IgLesias Ponce de LeÓn, Ma Josefa

1993 Reseña de The Ethnoarchaeology of Refuse Disposal, editado por Edward Staski y Livingstone D. Sutro. Revista Española de Antropología Americana 23: 256-258.

LaCadena García-Gallo, Alfonso

2005 «Excavación en el recinto cuadrilobulado de la Plaza A de Machaquilá», en Proyecto: "La entidad política de Machaquilá durante el ClásicoTardío y Terminal. Informe de la Temporada 2005, de Andrés Ciudad et al., pp. 8-112. Informe entregado al Ministerio de Ciencia y Tecnología, Madrid.

Lacadena García-Gallo, Alfonso y Ma Josefa Iglesias Ponce de León

2006 «La recreación del espacio mítico de La Montaña de las Flores en un palacio de Machaquila, Petén», en XIX Simposio de Investigaciones Arqueológicas de Guatemala, 2005, Juan Pedro Laporte, Bárbara Arroyo y Héctor Mejía, eds., pp. 589599. Guatemala: Museo Nacional de Arqueología y Etnología. 
LAPORTE, Juan Pedro

1995 «Una actualización a la secuencia cerámica del área de Dolores, Petén», en Revista del Atlas Arqueológico de Guatemala, vol. 3, pp. 35-64. Guatemala: Instituto de Antropología e Historia.

2003 «La tradición funeraria prehispánica en la región de Petén, Guatemala: Una visión desde Tikal y otras ciudades», en Antropología de la eternidad: la muerte en la cultura Maya, Andrés Ciudad, Mario Humberto Ruz y Ma Josefa Iglesias, eds., pp. 49-76. Madrid: Sociedad Española de Estudios Mayas y Centro de Estudios MayasUNAM.

2007 La secuencia cerámica del Sureste de Petén: tipos, cifras, localidades, y la historia del asentamiento. Serie Monografías, 3. Guatemala: Atlas Arqueológico de Guatemala. Documento electrónico, $<$ http://www.atlasarqueologico.com/monografias. php?idm=10>, con acceso el 2/12/2010.

LAPORTE, Juan Pedro y Marco Tulio Alvarado

1999 «El periodo Preclásico en el sureste de Petén: asentamiento, arquitectura, cerámica», en XII Simposio de Investigaciones Arqueológicas en Guatemala, 1998, Juan Pedro Laporte y Héctor Escobedo, eds., pp. 79-98. Guatemala: Museo Nacional de Arqueología y Etnología.

Laporte, Juan Pedro, Lilian A. Corzo, Héctor L. Escobedo, Rosa Ma Flores, K. Isabel Izaguirre, Nancy Monterroso, Paulino I. Morales, Carmen E. Ramos, Irma Rodas, Julio

A. RoldÁn, Franklin Solares y Bernard HeRmes

1993 La secuencia cerámica del valle de Dolores, Petén: Las unidades cerámicas. Atlas Arqueológico de Guatemala, $n^{\circ} 1$. Guatemala: Instituto de Antropología e Historia - Universidad de San Carlos.

LAPORTE, Juan Pedro y Carlos H. HeRman

2003 «Trabajos no divulgados del Proyecto Nacional Tikal, parte 3: nueva información sobre la exploración de la Zona Norte (Estructura 3D-43)», en XVI Simposio de Investigaciones Arqueológicas en Guatemala, 2002, Juan Pedro Laporte, Bárbara Arroyo, Héctor Escobedo y Héctor Mejía, eds., pp. 359-378. Guatemala: Museo Nacional de Arqueología y Etnología.

LinCOLN, Charles E.

1985 «Ceramics and Ceramic Chronology», en A Consideration of the Early Classic Period in the Maya Lowlands, Gordon R. Willey y Peter Mathews, eds., pp. 55-94. Institute for Mesoamerican Studies, pub.10. Albany: State University of New York.

Merwin, Raymond E. y George C. VAILlant

1932 The Ruins of Holmul, Guatemala. Memoirs of the Peabody Museum, vol.3 (2). Cambridge: Harvard University.

Orrego Corzo, Miguel y Carlos Rudy Larios Villalta

1983 Reporte de las investigaciones arqueológicas en el Grupo 5E-11, Tikal. Guatemala: Instituto de Antropología e Historia.

RODAS, Irma y Juan Pedro LAPORTE

1995 «Aktun Ak’Ab: Una cueva asociada al resumidero del río Xa'an, Dolores, Petén», en VIII Simposio de Investigaciones Arqueológicas en Guatemala, 1994, Juan Pedro Laporte y Héctor Escobedo, eds., pp. 629-650. Guatemala: Museo Nacional de Arqueología y Etnología. 
SABLOFF, Jeremy A.

1975 Excavations at Seibal: The Ceramics. Memoirs of the Peabody Museum, vol. 13 (2). Cambridge: Harvard University.

STASKI, Edward y Livingstone D. SuTro (eds.)

1991 The Ethnoarchaeology of Refuse Disposal. Anthropological Research Papers, 42. Tempe: Arizona State University.

VAILlant, George C.

1927 The Chronological Significance of Maya Ceramics. Tesis Doctoral. Cambridge: Harvard University. 